\title{
Multi-Terminal DC Fault Identification for MMC-HVDC Systems based on Modal Analysis -A Localized Protection Scheme
}

Nougain, Vaibhav; Mishra, Sukumar; Misyris, George S.; Chatzivasileiadis, Spyros; Chatzivasileiadis, Spyros

\section{Published in:}

IEEE Journal of Emerging and Selected Topics in Power Electronics

Link to article, DOI:

10.1109/JESTPE.2021.3068800

Publication date:

2021

Document Version

Peer reviewed version

Link back to DTU Orbit

Citation $(A P A)$ :

Nougain, V., Mishra, S., Misyris, G. S., Chatzivasileiadis, S., \& Chatzivasileiadis, S. (2021). Multi-Terminal DC Fault Identification for MMC-HVDC Systems based on Modal Analysis - A Localized Protection Scheme. IEEE Journal of Emerging and Selected Topics in Power Electronics, 9(6), 6650 - 6661.

https://doi.org/10.1109/JESTPE.2021.3068800

\section{General rights}

Copyright and moral rights for the publications made accessible in the public portal are retained by the authors and/or other copyright owners and it is a condition of accessing publications that users recognise and abide by the legal requirements associated with these rights.

- Users may download and print one copy of any publication from the public portal for the purpose of private study or research.

- You may not further distribute the material or use it for any profit-making activity or commercial gain

- You may freely distribute the URL identifying the publication in the public portal 


\title{
Multi-Terminal DC Fault Identification for MMC-HVDC Systems based on Modal Analysis - A Localized Protection Scheme
}

\author{
Vaibhav Nougain, Sukumar Mishra, Senior Member, IEEE, George S. Misyris, Student Member, IEEE \\ and Spyros Chatzivasileiadis, Senior Member, IEEE
}

\begin{abstract}
For the purpose of DC fault identification in multiterminal modular multilevel converter (MMC) high voltage DC (HVDC) systems, the proposed work addresses the issues of localized protection schemes. The proposed work is focused on selectivity issues such as differentiating between forward external and internal faults, and classification of type of fault contingency i.e., pole to pole (PTP) or pole to ground (PTG) in the system. The scheme uses equivalent network of multiterminal MMC-HVDC systems for DC fault identification. Modal transformation is used to analyse line-mode and zero-mode voltage across the current limiting reactor (CLR) for different possible contingencies in the system. A maloperation region has been defined to address the issue of selectivity of internal HIFs and external low impedance faults (LIFs). Rate of change of DC voltage $\left(d U_{d c} / d t\right)$ is used as the mitigation technique to differentiate a HIF as high as $1000 \Omega$. Further, a sensitivity function is formulated which gives the variation of decisive parameters i.e., line-mode voltage and zero-mode voltage with respect to change in fault resistance and value of current limiting reactor. PSCAD/EMTDC based simulations are used to validate the performance of the proposed scheme. The scheme is validated in terms of detection time, robustness to WGN in measurement, security for AC faults, DC circuit breakers (DCCB) operation, power reversal (load transients).
\end{abstract}

Index Terms-MMC-HVDC, localized protection, fault identification, DC fault.

\section{INTRODUCTION}

$\mathbf{T}$ HE idea of better scalability and very low harmonics has made modular multilevel converter (MMC) technology effectively applicable for HVDC systems with the objective of transmitting large offshore wind energy over long distances [1]-[3]. Multi-terminal MMC-HVDC configuration ensuring system reliability with continuous operation of power transfer even under DC faults has resulted in practical offshore wind projects like European "Super Grid" [3] and the four-terminal 3000 MW HVDC project in Zhangbei, China [13]. However, in case of a multi-terminal configuration, since there are numerous MMC terminals finding different paths (with different impedances) to contribute

Vaibhav Nougain and Sukumar Mishra are with the Department of Electrical Engineering, Indian Institute of Technology, Delhi, New Delhi, 110016 India. e-mail: (nougainvaibhav@gmail.com, sukumariitdelhi@gmail.com).

George S. Misyris and S. Chatzivasileiadis are with the Center for Electric Power and Energy (CEE), Technical University of Denmark (DTU), Kgs. Lyngby, Denmark. e-mail: (gmisy@elektro.dtu.dk, spchatz@elektro.dtu.dk).

George S. Misyris and S. Chatzivasileiadis acknowledge the support of Innovation Fund Denmark through the project "multiDC", Grant No. 615400020B. to the fault current, the fault current is relatively higher compared to the conventional point to point HVDC system [4], which has a contribution from only two terminals. In order to mitigate the damage to the power electronic switches of MMC converters due to the fault current, direct current circuit breakers (DCCB) are used to isolate the faulty part of the network in time, ensuring continuous power transfer in the multi-terminal MMC-HVDC systems [5]. Therefore, a rapid and reliable fault identification scheme for DC faults is an indispensable requirement for such configurations.

Considering the fault identification schemes for multiterminal MMC-HVDC systems in the literature, travelling wave (TW) based localized methods are effective and hence, popular. The authors in [6] employ rate of change of local current, synonym of ROCOC. The authors in [7] take the rate of change of voltage (ROCOV) of the current limiting reactor (CLR) to identify the fault upon inception. However, high impedance faults (HIFs) and the presence of white gaussian noise (WGN) jeopardize the reliability of the schemes in [6]-[7]. The rate of change of ROCOV of the CLR has been taken as the decisive parameter by authors in [8] working on the problem of maloperation due to WGN. However, the decision on minimum time window required for noise immunisation is a tricky affair for complex systems with multiple converters [9]. The authors in [10] take the transient energy ratio of DC Filter Link as the decisive parameter for fault identification whereas the authors in [11] employ the CLR Power. The authors in [12] propose a scheme integrating rate of transient voltages and communication based backup protection. The schemes in [10]-[12] work effectively for HIFs. However, the performance of such schemes is sensitive to fault type and fault resistance; at the same time the impact of noise [14] has also not been discussed in [10]-[12]. In addition, as pointed in [14], accurately distinguishing between external and internal faults is a problem unresolved with schemes proposed in [6]-[12].

Working on the aspect of selectivity for external and internal faults, the authors in [13] use frequency domain based ratio of transient voltages to distinguish between external and internal faults in the system. However, the scheme has weakness to WGN [14]. The authors in [14] employ phasemodal transformation to propose an elaborate analysis working on the effect of WGN and distinguishing between 
external and internal faults. The scheme proposed in [14] gives a good theoretical foundation to classify the faults based on line-mode and zero-mode voltage across the current limiting reactor. The scheme in [14] covers the broad analysis under forward external faults. However while distinguishing between internal HIFs and forward external low impedance faults (LIFs) using line-mode voltage, the scheme may have selectivity issues. This is a result of not considering the sensitivity of the decisive parameters with respect to fault resistance, $R_{f}$. The line mode and zero mode voltages used to analyse different fault contingencies in [14] are sensitive to fault resistance. As a result of which, they show similar characteristics for forward external LIFs and internal HIFs. This means that method proposed in [14] is prone to maloperation for internal HIFs and forward external LIFs. The contribution of the proposed work is inclusion of fault resistance in the mathematical analysis in order to classify forward external LIFs and internal HIFs. ROCOV ( $\mathrm{dU}_{d c} / \mathrm{dt}$ ) with threshold, $M_{s e t}$ is used to classify the similar ranging line-mode voltage of mentioned family of faults. This makes the mode voltage based classification implementable for HIFs up to $1000 \Omega$. The proposed work defines a maloperation region analysis to classify between low impedance forward external and high impedance internal faults in a system. The proposed work formulates a sensitivity function to analyse the variation of decisive parameters in the proposed protection approach with respect to fault parameters i.e., fault resistance and value of current limiting reactor in the system.

The rest of the paper is organized as follows. Section II gives the test system configuration elaborating the MMC equivalent model, the overhead line (OHL) equivalent model and system equivalent network for different fault contingencies. Section III gives the fault analysis for different fault contingency in the system based on line-mode and zero-mode voltage. This is followed by the concept of maloperation region for internal HIFs and external LIFs and its mitigation. Section IV presents the proposed fault identification algorithm. Section V validates the scheme for different events. It also gives the sensitivity analysis of mode-voltages with respect to fault parameters. Finally, section VI concludes the paper.

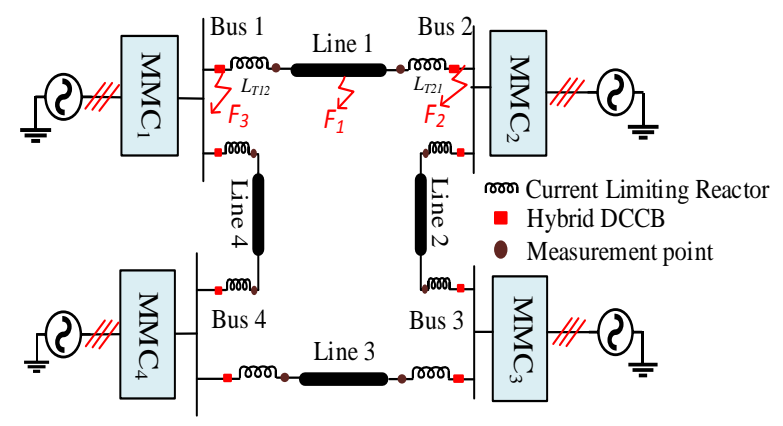

Fig. 1: CIGRE 4-bus Multi-terminal benchmark Grid [17]

\section{Test System Configuration}

CIGRE 4-bus multi-terminal benchmark grid [17] is considered for the MMC-HVDC configuration as the test system to validate the proposed fault identification scheme [refer to Fig. 1]. Current limiting reactors $\left(L_{T m n}\right)$ are employed to mitigate the rate of rise of current in case of a fault contingency in the system [18]. Fault $F_{1}$ shows a fault in line 1 at a specific location whereas fault $F_{2}$ shows a forward external fault and $F_{3}$ shows a backward external fault in the system. A bipolar line configuration with frequencydependent transmission model (FDTL) for overhead lines (OHL) is considered for the system [24].

\section{A. MMC simplified equivalent model}

The MMC configuration is represented with its simplified equivalent model [25] as shown in Fig. 2. The parameters in the simplified model are defined as, $R_{M M C}=\frac{2}{3}\left(R+\Sigma R_{o n}\right)$, $L_{M M C}=\frac{2}{3} L, C_{M M C}=6 \frac{C}{N}$. Here $R$ is the arm resistance and $\Sigma R_{o n}$ is the sum of the on-state resistances of all IGBT modules [25]. $L$ is the arm inductance, $C$ is the sub-module (SM) capacitance and $N$ gives the number of SMs per arm. $L_{T m n}$ is the CLR, whereas $i_{s 1 p}$ and $i_{s 1 n}$ are the source currents for the positive and negative pole. $U_{L 12 \_p}$ and $U_{L 12 \_n}$ are the positive and negative pole voltages across the CLR, whereas $i_{L 12 \_} p$ and $i_{L 12 \_n}$ are the positive and negative pole currents through the CLR.

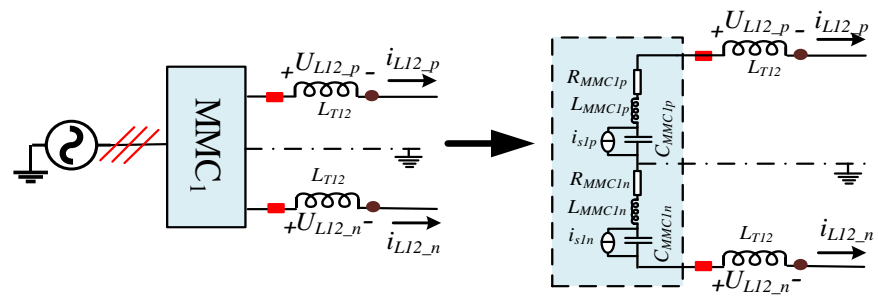

Fig. 2: Equivalent model of MMC system

\section{B. OHL equivalent model}

Distributed parameter model of a bipolar OHL is shown in Fig. 3. $C_{g 0}$ and $C_{p 0}$ are defined as grounding capacitor and phase capacitor per unit length. $L_{m n 0}, R_{m n 0}$ and $M_{m n 0}$ are defined as the self-inductance, resistance and mutual inductance of line $m n$ per unit length [14].

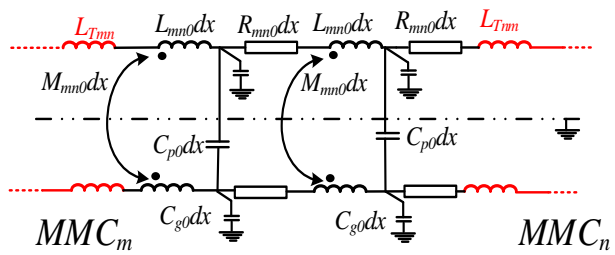

Fig. 3: Distributed parameter model of bipolar OHL

Considering the parameters of multi-terminal MMC-HVDC configuration, the fault interruption needs to be within $3 \mathrm{~ms}$ of fault inception [13]-[14]. This period sees fault current contribution from the DC capacitance of MMC and the grounding and phase capacitance of line. The equivalent DC capacitor of MMC is around $10^{2}-10^{3} \mu \mathrm{F}$ [21] while grounding capacitor and phase capacitor are within 0.01 $\mu \mathrm{F} / \mathrm{km}$ [20]. Hence, the fault contribution from the grounding and phase capacitance of OHL can be ignored [22]. The grounding capacitor and phase capacitor for underground cables (UGC) can be as high as $0.5 \mu \mathrm{F} / \mathrm{km}$. Hence, the conclusion is valid for short to medium UGC as well. 


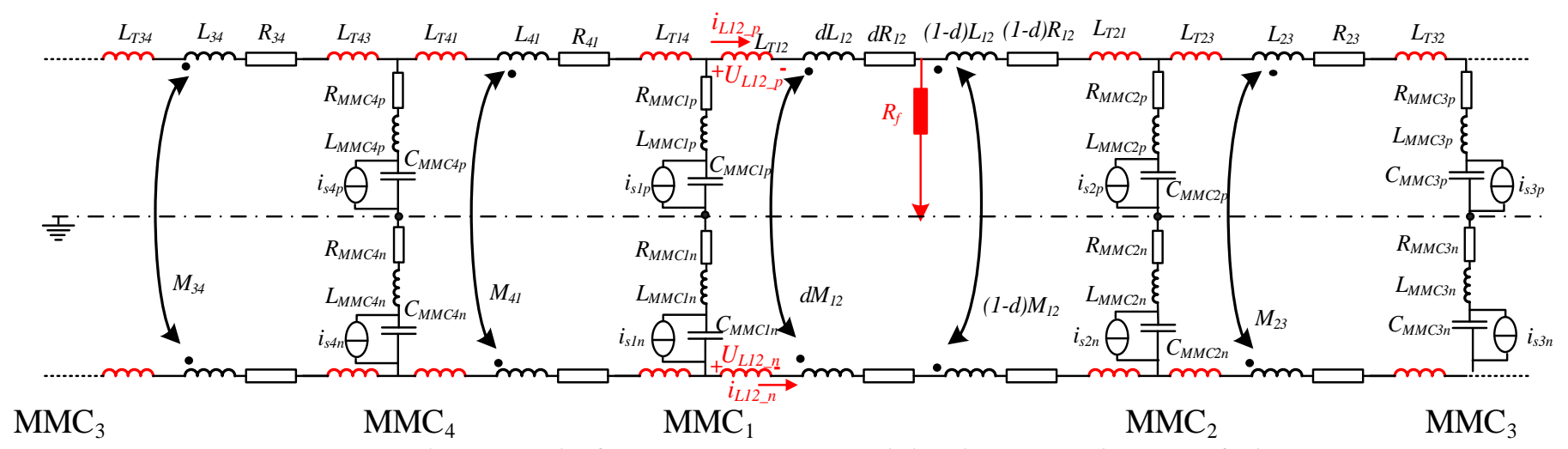

Fig. 4: Equivalent network of MMC-HVDC system with bipolar OHL under P-PTG fault

\section{Equivalent network during a fault contingency}

Combining the MMC equivalent model and OHL equivalent model, Fig. 4 shows the equivalent network of MMCHVDC system with bipolar OHL during ( $P-P T G)$ fault. The fault location $d$ is the percentage of unit length with fault resistance $R_{f}$. In order to decouple the dependency of poles of transmission lines under pole to ground (PTG) faults, phase-modal transformation [14] is incorporated to the mentioned equivalent network. This phase-modal transformation for bipolar DC is analogous to symmetrical component transformation in $3 \phi \mathrm{AC}$. The phase-modal transformation is mathematically expressed as:

$$
\left[\begin{array}{l}
x_{l} \\
x_{0}
\end{array}\right]=\left[\begin{array}{cc}
1 & -1 \\
1 & 1
\end{array}\right]\left[\begin{array}{l}
x_{p} \\
x_{n}
\end{array}\right]
$$

$x_{l}$ and $x_{0}$ are defined as the line-mode and zero-mode variables whereas $x_{p}$ and $x_{n}$ are the positive-pole and negative-pole variables. The line-mode and the zero-mode equivalent network for fault $F_{1}$ in Fig. 1 is shown in Fig. 5 where $C_{14}$ and $C_{23}$ are the equivalent DC link terminal capacitances for line 14 and 23. $Z_{14}$ and $Z_{23}$ are the equivalent impedance for line 14 and 23 and are defined as:

$$
\left\{\begin{array}{l}
Z_{14}(j \omega)=j \omega\left(L_{41}+L_{T 41}+\frac{1}{2} L_{M M C 4}\right)+R_{41}+\frac{1}{2} R_{M M C 4} \\
Z_{23}(j \omega)=j \omega\left(L_{23}+L_{T 32}+\frac{1}{2} L_{M M C 3}\right)+R_{23}+\frac{1}{2} R_{M M C 3}
\end{array}\right.
$$

The mutual inductance of OHL is also transformed into $L_{m n_{-} l}$ and $L_{m n \_} 0$ as:

$$
\left\{\begin{array}{l}
L_{m n \_l}=L_{m n}-M_{m n} \\
L_{m n \_0}=L_{m n}+M_{m n}
\end{array}\right.
$$

\section{FAUlt ANALYSIS FOR DIFFERENT FAULT CONTINGENCIES}

\section{A. Internal pole to ground (PTG) fault contingency}

For an internal positive-pole to ground $(P-P T G)$ fault contingency shown as $F_{1}$ in Fig. $1, U_{f_{-} p}(j \omega)=i_{f_{-} p}(j \omega) R_{f}$ and $i_{f_{-} n}(j \omega)=0$. Using the phase-modal transformation, the conditions are transformed to the form:

$$
\left\{\begin{array}{l}
U_{f_{-} l}(j \omega)+U_{f_{-} 0}(j \omega)=2 i_{f_{-} l}(j \omega) R_{f} \\
i_{f_{-} l}(j \omega)=I_{f_{-} 0}(j \omega)
\end{array}\right.
$$

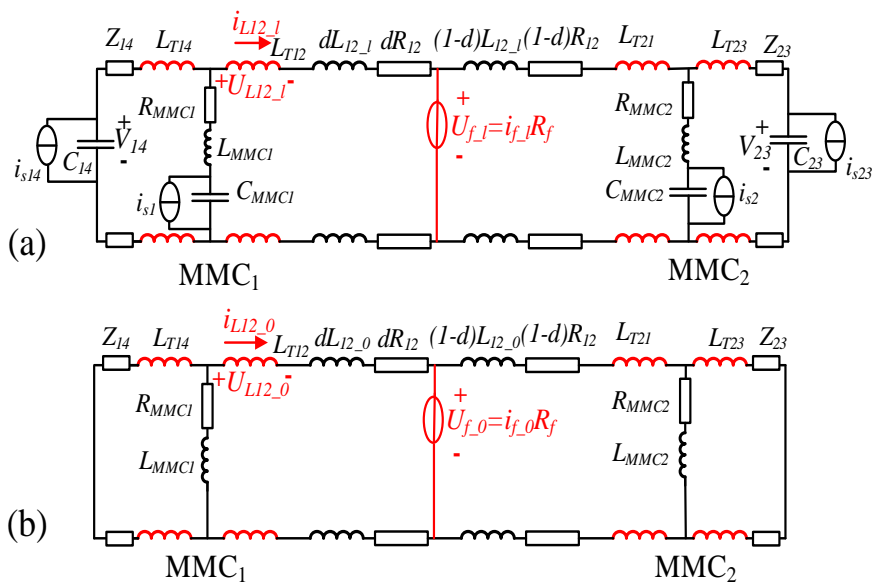

Fig. 5: Simplified Equivalent network for (a) line-mode, (b) zero-mode

Considering equation 4 , the combined equivalent mode network for an internal P-PTG is shown in Fig. 6. The idea is to derive the line-mode voltage $\left(U_{L 12 \_}(j \omega)\right)$ and zero-mode voltage $\left(U_{L 12 \_0}(j \omega)\right)$ across the CLR $\left(L_{T m n}\right)$.

$$
\left\{\begin{aligned}
U_{L 12 \_}(j \omega)= & \frac{j \omega L_{T 12} U_{d c}}{Z_{1}+Z_{2} \|\left[\left(Z_{3} \| Z_{4}\right)+2 R_{f}\right]} \times \frac{Z_{2} \|\left[\left(Z_{3} \| Z_{4}\right)+2 R_{f}\right]}{Z_{3}} \\
& +\frac{j \omega L_{T 12} U_{d c}}{Z_{2}+Z_{1} \|\left[\left(Z_{3} \| Z_{4}\right)+2 R_{f}\right]} \times \frac{Z_{1} \|\left[\left(Z_{3} \| Z_{4}\right)+2 R_{f}\right]}{Z_{3}} \\
U_{L 12 \_1}(j \omega)= & -\frac{j \omega L_{T 12} U_{d c}}{Z_{2}+Z_{1} \|\left[\left(Z_{3} \| Z_{4}\right)+2 R_{f}\right]} \times \frac{Z_{1} \|\left[\left(Z_{3} \| Z_{4}\right)+2 R_{f}\right]}{Z_{1}} \\
& +\frac{j \omega L_{T 12} U_{d c}}{Z_{1}+Z_{2} \|\left[\left(Z_{3} \| Z_{4}\right)+2 R_{f}\right]}
\end{aligned}\right.
$$

where $U_{d c}$ is pre-fault rated DC voltage of MMC-HVDC system. The impedances, $Z_{1}-Z_{4}$ are frequency-dependent functions. Also, $R_{M M C n}$ and $R_{m n}$ are neglected in the calculation due to small magnitude for long transmission lines. For simplicity, impedances are written as $Z_{i}$ and not $Z_{i}(j \omega)$ 


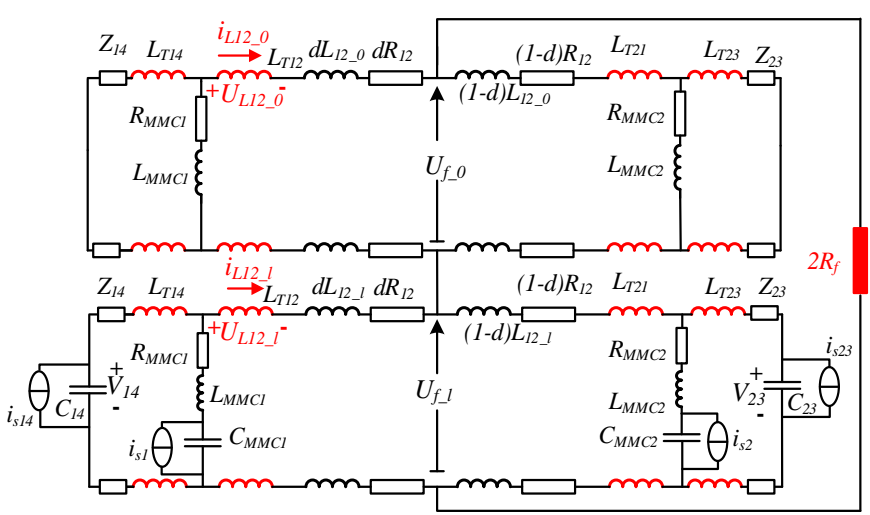

Fig. 6: Combined equivalent mode network for an internal PTG

and are mathematically defined as:

$$
\left\{\begin{array}{l}
Z_{1}=\left[2\left(Z_{14}+j \omega L_{T 14}\right) \| j \omega L_{M M C 1}\right]+2 j \omega\left(L_{T 12}+d L_{12 \_l}\right) \\
Z_{2}=\left[2\left(Z_{23}+j \omega L_{T 23}\right) \| j \omega L_{M M C 2}\right]+2 j \omega\left(L_{T 21}+(1-d) L_{12 \_l}\right) \\
Z_{3}=\left[2\left(Z_{14}+j \omega L_{T 14}\right) \| j \omega L_{M M C 1}\right]+2 j \omega\left(L_{T 12}+d L_{12 \_0}\right) \\
Z_{4}=\left[2\left(Z_{23}+j \omega L_{T 23}\right) \| j \omega L_{M M C 2}\right]+2 j \omega\left(L_{T 21}+(1-d) L_{12 \_}\right)
\end{array}\right.
$$

Similarly, the line-mode voltage and zero-mode voltage for Negative-pole to ground $(N-P T G)$ are defined as:

$$
\left\{\begin{aligned}
U_{L 12 \_0}(j \omega)= & -\frac{j \omega L_{T 12} U_{d c}}{Z_{1}+Z_{2} \|\left[\left(Z_{3} \| Z_{4}\right)+2 R_{f}\right]} \times \frac{Z_{2} \|\left[\left(Z_{3} \| Z_{4}\right)+2 R_{f}\right]}{Z_{3}} \\
& -\frac{j \omega L_{T 12} U_{d c}}{Z_{2}+Z_{1} \|\left[\left(Z_{3} \| Z_{4}\right)+2 R_{f}\right]} \times \frac{Z_{1} \|\left[\left(Z_{3} \| Z_{4}\right)+2 R_{f}\right]}{Z_{3}} \\
U_{L 12 \_1}(j \omega)= & -\frac{j \omega L_{T 12} U_{d c}}{Z_{2}+Z_{1} \|\left[\left(Z_{3} \| Z_{4}\right)+2 R_{f}\right]} \times \frac{Z_{1} \|\left[\left(Z_{3} \| Z_{4}\right)+2 R_{f}\right]}{Z_{1}} \\
& +\frac{j \omega L_{T 12} U_{d c}}{Z_{1}+Z_{2} \|\left[\left(Z_{3} \| Z_{4}\right)+2 R_{f}\right]}
\end{aligned}\right.
$$

\section{B. External PTG fault contingency}

1) Backward External PTG fault contingency: For a backward external $P T G$ fault contingency, $F_{3}$ (see Fig. 1), the combined equivalent mode network is similar to Fig. 7 where the fault occurs behind $L_{T 12}$ instead of after $L_{T 12}$ (refer to Fig. 7). The line-mode voltage and zero-mode voltage for a backward external PTG fault are defined as:

$$
\left\{\begin{aligned}
U_{L 12 \_0}(j \omega)= & -\frac{j \omega L_{T 12} U_{d c}}{Z_{5}+Z_{6} \|\left[\left(Z_{6} \| Z_{7}\right)+2 R_{f}\right]} \times \frac{Z_{6} \|\left[\left(Z_{6} \| Z_{7}\right)+2 R_{f}\right]}{Z_{7}} \\
& -\frac{j \omega L_{T 12} U_{d c}}{Z_{6}+Z_{5} \|\left[\left(Z_{6} \| Z_{7}\right)+2 R_{f}\right]} \times \frac{Z_{5} \|\left[\left(Z_{6} \| Z_{7}\right)+2 R_{f}\right]}{Z_{7}} \\
U_{L 12 \_1}(j \omega)= & \frac{j \omega L_{T 12} U_{d c}}{Z_{6}+Z_{5} \|\left[\left(Z_{6} \| Z_{7}\right)+2 R_{f}\right]} \times \frac{Z_{5} \|\left[\left(Z_{6} \| Z_{7}\right)+2 R_{f}\right]}{Z_{5}} \\
& -\frac{j \omega L_{T 12} U_{d c}}{Z_{5}+Z_{6} \|\left[\left(Z_{6} \| Z_{7}\right)+2 R_{f}\right]}
\end{aligned}\right.
$$

TABLE I: Polarity of line-mode and zero-mode voltages for different $P T G$ faults

\begin{tabular}{ccc}
\hline \multirow{2}{*}{ Fault Contingency } & \multicolumn{2}{c}{ Polarity } \\
\cline { 2 - 3 } & $U_{L 12 \_0}$ & $U_{L 12 \_1}$ \\
\hline $\boldsymbol{P}-\boldsymbol{P T G}$ & Positive & Positive \\
$\boldsymbol{N}-\boldsymbol{P T G}$ & Negative & Positive \\
Backward External & Negative & Negative \\
Forward External & Positive & Positive \\
\hline
\end{tabular}

where the impedances, $Z_{5}-Z_{7}$ are defined as:

$$
\left\{\begin{array}{l}
Z_{5}=\left[2\left(Z_{23}+j \omega L_{T 23}\right) \| j \omega L_{M M C 2}+\right]+2 j \omega\left(L_{T 12}+L_{T 21}+L_{12 \_l}\right) \\
Z_{6}=\left[2\left(Z_{14}+j \omega L_{T 14}\right) \| j \omega L_{M M C 1}\right] \\
Z_{7}=\left[2\left(Z_{23}+j \omega L_{T 23}\right) \| j \omega L_{M M C 2}\right]+2 j \omega\left(L_{T 12}+L_{T 21}+L_{12 \_0}\right)
\end{array}\right.
$$

2) Forward External PTG fault contingency: For a forward external $P T G$ fault contingency, $F_{2}$ (see Fig. 1), the combined equivalent mode network is shown in Fig. 7. The linemode voltage and zero-mode voltage for a forward external $P T G$ fault are defined as:

$$
\left\{\begin{aligned}
U_{L 12 \_0}(j \omega)= & \frac{j \omega L_{T 12} U_{d c}}{Z_{8}+Z_{9} \|\left[\left(Z_{9} \| Z_{10}\right)+2 R_{f}\right]} \times \frac{Z_{9} \|\left[\left(Z_{9} \| Z_{10}\right)+2 R_{f}\right]}{Z_{10}} \\
& +\frac{j \omega L_{T 12} U_{d c}}{Z_{9}+Z_{8} \|\left[\left(Z_{9} \| Z_{10}\right)+2 R_{f}\right]} \times \frac{Z_{8} \|\left[\left(Z_{9} \| Z_{10}\right)+2 R_{f}\right]}{Z_{10}} \\
U_{L 12 \_1}(j \omega)= & -\frac{j \omega L_{T 12} U_{d c}}{Z_{9}+Z_{8} \|\left[\left(Z_{9} \| Z_{10}\right)+2 R_{f}\right]} \times \frac{Z_{8} \|\left[\left(Z_{9} \| Z_{10}\right)+2 R_{f}\right]}{Z_{8}} \\
& +\frac{j \omega L_{T 12} U_{d c}}{Z_{8}+Z_{9} \|\left[\left(Z_{9} \| Z_{10}\right)+2 R_{f}\right]}
\end{aligned}\right.
$$

where the impedances, $Z_{8}-Z_{10}$ are defined as:

$$
\left\{\begin{aligned}
Z_{8} & =\left[2\left(Z_{14}+j \omega L_{T 14}\right) \| j \omega L_{M M C 1}\right]+2 j \omega\left(L_{T 12}+L_{T 21}+L_{12 \_}\right) \\
Z_{9} & =\left[2\left(Z_{23}+j \omega L_{T 23}\right) \| j \omega L_{M M C 2}\right] \\
Z_{10} & =\left[2\left(Z_{14}+j \omega L_{T 14}\right) \| j \omega L_{M M C 1}\right]+2 j \omega\left(L_{T 12}+L_{T 21}+L_{12 \_}\right)
\end{aligned}\right.
$$

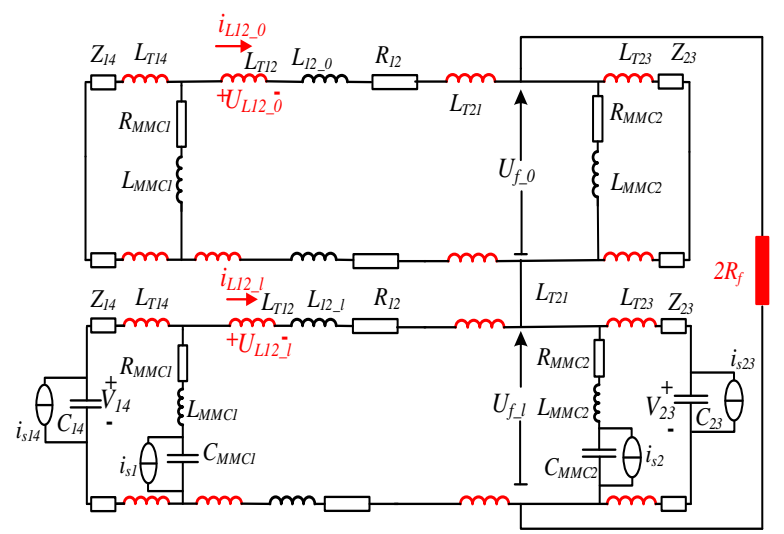

Fig. 7: Combined equivalent mode network for a forward external PTG 
TABLE II: Polarity of line-mode and zero-mode voltages for different $P T P$ faults

\begin{tabular}{ccc}
\hline \multirow{2}{*}{ Fault Contingency } & \multicolumn{2}{c}{ Polarity } \\
\cline { 2 - 3 } & $U_{L 12 \_0}$ & $U_{L 12 \_1}$ \\
\hline PTP & 0 & Positive \\
Backward External & 0 & Negative \\
Forward External & 0 & Positive \\
\hline
\end{tabular}

\section{Internal PTP fault contingency}

For a PTP fault contingency $\left(\mathrm{F}_{1}\right)$ in the system shown in Fig. $1, \quad U_{f_{-} p}(j \omega)-U_{f_{-} n}(j \omega)=i_{f_{-}}(j \omega) R_{f}$ and $i_{f_{-} p}(j \omega)+i_{f_{-} n}(j \omega)=0$. Applying phase-modal transformation, the conditions are transformed to the form:

$$
\left\{\begin{array}{l}
U_{f_{-} l}(j \omega)=i_{f_{-} l}(j \omega) R_{f} \\
i_{f_{-} 0}(j \omega)=0
\end{array}\right.
$$

(a)

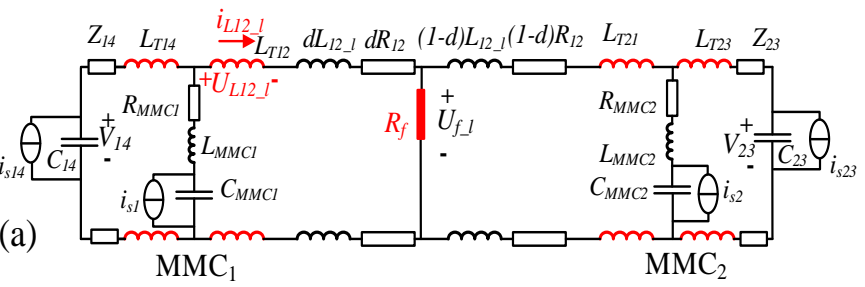

(b)

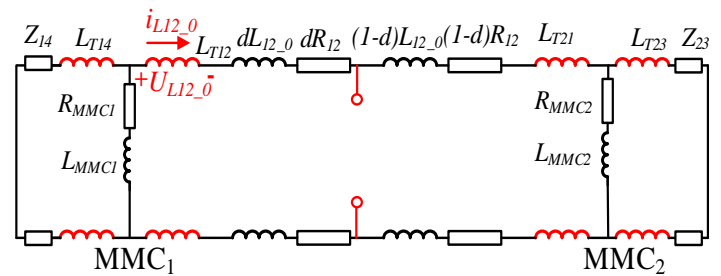

Fig. 8: Combined equivalent mode network for an internal PTP

Considering equation 12, the equivalent mode network for an internal PTP fault is shown in Fig. 8. The line-mode voltage and the zero-mode voltage for internal PTP are defined as:

$$
\left\{\begin{array}{l}
U_{L 12 \_0}(j \omega)=0 \\
U_{L 12 \_1}(j \omega)=\frac{j \omega L_{T 12} U_{d c}}{Z_{1}+Z_{2} \| R_{f}}-\frac{j \omega L_{T 12} U_{d c}}{Z_{2}+Z_{1} \| R_{f}} \times \frac{Z_{1} \| R_{f}}{Z_{1}}
\end{array}\right.
$$

\section{External PTP fault contingency}

Similar to the previous subsection, the line-mode voltage and the zero-mode voltage for a backward external PTP fault are defined as:

$$
\left\{\begin{array}{l}
U_{L 12 \_0}(j \omega)=0 \\
U_{L 12 \_1}(j \omega)=-\frac{j \omega L_{T 12} U_{d c}}{Z_{5}+Z_{6} \| R_{f}}+\frac{j \omega L_{T 12} U_{d c}}{Z_{6}+Z_{5} \| R_{f}} \times \frac{Z_{5} \| R_{f}}{Z_{5}}
\end{array}\right.
$$

Also, the line-mode voltage and the zero-mode voltage for a forward external PTP fault are defined as:

$$
\left\{\begin{array}{l}
U_{L 12 \_0}(j \omega)=0 \\
U_{L 12 \_1}(j \omega)=\frac{j \omega L_{T 12} U_{d c}}{Z_{8}+Z_{9} \| R_{f}}-\frac{j \omega L_{T 12} U_{d c}}{Z_{9}+Z_{8} \| R_{f}} \times \frac{Z_{8} \| R_{f}}{Z_{8}}
\end{array}\right.
$$

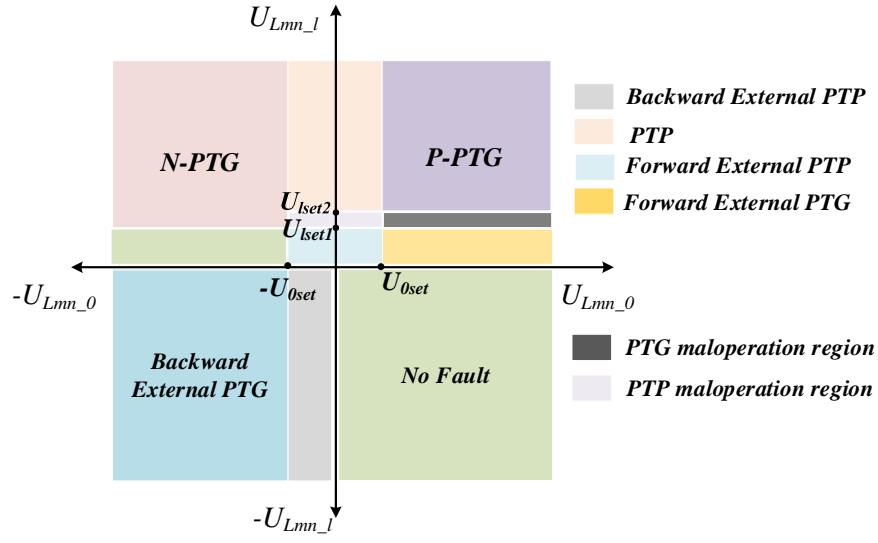

Fig. 9: Classification of different fault contingencies based on

$$
U_{L m n_{-} l} \text { and } U_{L m n_{-} 0}
$$

The line-mode and zero-mode voltages are evaluated for different fault contingencies. PTG fault is classified on the basis of polarity of $U_{L 12 \_1}$ and $U_{L 12 \_0}$ in Table I whereas PTP is classified in Table II. The combined classification of PTP and PTG fault contingency is shown in Fig. 9. The zero-mode voltage threshold is set to be $U_{0 s e t}$ in order to distinguish between $P T P$ and $P T G$ fault. Similar range of line mode voltage for forward external LIFs and internal HIFs is shown as PTG maloperation region and PTP maloperation region in Fig. 9. The maloperation region is defined by the area between $\mathrm{U}_{\text {lset } 0}$ and $\mathrm{U}_{\text {lset } 1}$. Fig. 10 shows line mode voltage $\left(\mathrm{U}_{L 12 \_l}\right)$ for forward external LIFs and internal HIFs (detailed in Table VI). It is evident that there exists fault region where an external fault can lead to relay tripping. Hence, jeopardizing the selectivity. The maloperation region shown in Fig. 10 consists of two types of faults i.e., external LIFs and internal HIFs. The parameter, $\left|\mathrm{dU}_{d c} / d t\right|$ can be effectively used to differentiate a LIF and HIF as shown in Table VI. The analysis considers the maximum possible value of $\left|\mathrm{dU}_{d c} / d t\right|$ for internal HIFs along OHL fault location. Addressing the issue of HIFs, the scheme hence can detect a fault as high as $1000 \Omega$.

\section{Proposed Fault Identification Algorithm}

The fault identification algorithm employs rate of change of DC voltage $\left(d U_{d c} / d t\right)$ as the trigger signal. If the absolute slope is greater than the threshold, $D$ [refer section VI(A)], the algorithm evaluates $U_{L 12_{-} 0}$ and $U_{L 12_{1} 1}$. The decision on $D$ is discussed in Section VI(A). The first classification is based on the analysis of zero-mode voltage, $U_{L 12 \_0}$ where $P T P$ and $P T G$ family of faults are differentiated. The property of zeromode voltage, $\left|U_{L 12 \_}\right|<U_{0 \text { set }}$ for PTP family of faults (refer to Table II) is used for this purpose. The threshold, $U_{0 \text { set }}$ is defined $1 \mathrm{kV}$ for the practical implementation of the scheme. Once the PTP and PTG family of faults is classified, we refer to Table I and Table II to check the conditions for further classification of fault. As evident from the tables, the polarity of line-mode and zero-mode voltages differentiate the backward external faults from the other faults (forward external and internal). However, the classification 
TABLE III: Parameters implemented

\begin{tabular}{lll}
\hline \hline \multicolumn{1}{c}{ Symbol } & \multicolumn{1}{c}{ Quantity } & \multicolumn{1}{c}{ Range } \\
\hline$R_{M M C 1} / L_{M M C 1} / C_{M M C 1}$ & Parameters- $M M C_{1}$ & $192.4 \mathrm{~m} \Omega / 60 \mathrm{mH} / 300 \mu \mathrm{F}$ \\
$\mathrm{R}_{M M C 2} / L_{M M C 2} / C_{M M C 2}$ & Parameters- $M M C_{2}$ & $243.2 \mathrm{~m} \Omega / 77.3 \mathrm{mH} / 375 \mu \mathrm{F}$ \\
$\mathrm{R}_{M M C 3} / L_{M M C 3} / C_{M M C 3}$ & Parameters- $M M C_{3}$ & $684.8 \mathrm{~m} \Omega / 96 \mathrm{mH} / 240 \mu \mathrm{F}$ \\
$\mathrm{R}_{M M C 4} / L_{M M C 4} / C_{M M C 4}$ & Parameters- $M M C_{4}$ & $371.2 \mathrm{~m} \Omega / 72 \mathrm{mH} / 450 \mu \mathrm{F}$ \\
$\mathrm{C}_{g 0}, C_{p 0}$ & Grounding and phase Capacitor per unit length & $0.0078 \mu \mathrm{F} / \mathrm{km}, 0.0085 \mu \mathrm{F} / \mathrm{km}$ \\
$\mathrm{L}_{m n 0}, L_{T m n}$ & Self-inductance per unit length, Current Limiting reactor & $1.82 \mathrm{mH} / \mathrm{km}, 90 \mathrm{mH}-150 \mathrm{mH}$ \\
$\mathrm{R}_{m n 0}$ & Line Resistance per unit length & $102 \mathrm{~m} \Omega / \mathrm{km}$ \\
$\mathrm{OHL}_{1} / O H L_{2} / O H L_{3} / O H L_{4}$ & DC overhead line length & $300 \mathrm{~km} / 240 \mathrm{~km} / 150 \mathrm{~km} / 380 \mathrm{~km}$ \\
$\mathrm{D}_{0} \mathrm{U}_{0 \text { set }}$ & Threshold for $\left|d U_{d c} / d t\right|$, Threshold for zero-mode voltage & $100 \mathrm{kV} / \mathrm{ms}, 1 \mathrm{kV}$ \\
$\mathrm{U}_{l s e t 1}, U_{l s e t 2}$ & Threshold 1 and 2 for line-mode voltage & PTP- $170 \mathrm{kV}$, PTG- $85 \mathrm{kV}$, PTP- $300 \mathrm{kV}$, PTG- $150 \mathrm{kV}$ \\
$\mathrm{M}_{\text {set }}$ & Threshold of $d U_{d c} / d t$ to mitigate maloperation region & PTP- $3000 \mathrm{kV} / \mathrm{ms}$, PTG- $1500 \mathrm{kV} / \mathrm{ms}$, \\
\hline \hline
\end{tabular}
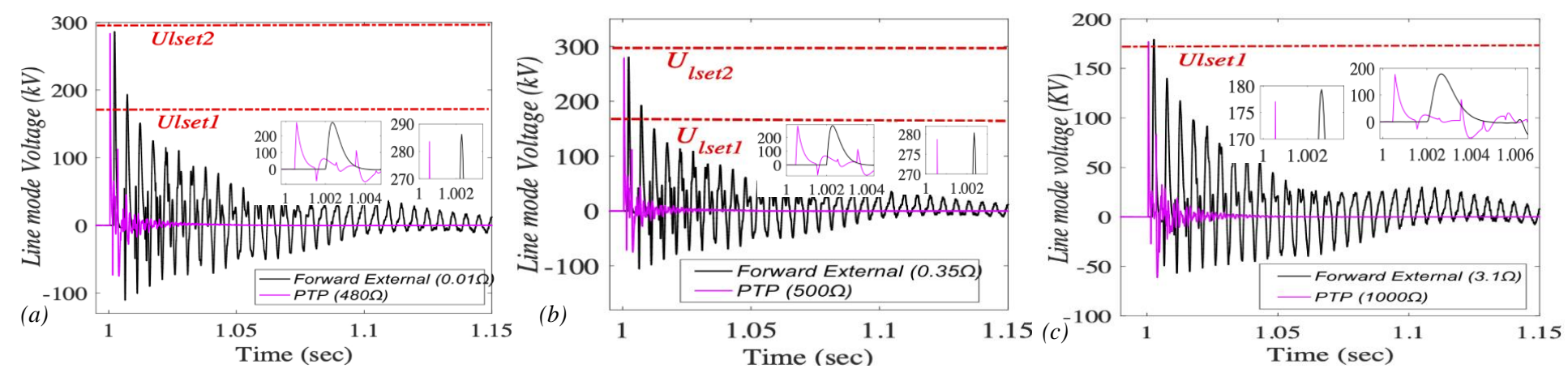

Fig. 10: Simulation validation for maloperation region for Line Mode Voltage $(\mathrm{kV})$ with Time (sec) for (a) Forward External $(0.01 \Omega)$, PTP $(480 \Omega)$, (b) Forward External $(0.35 \Omega)$, PTP $(500 \Omega)$, (c) Forward External $(3.1 \Omega)$, PTP $(1000 \Omega)$

of forward external and PTP internal or forward external and $P T G$ internal have a maloperation region where the differentiation between the internal and forward external fault is not possible looking into the line-mode voltage alone. Thresholds, $U_{l s e t 1}$ and $U_{l s e t 2}$ are defined to identify the maloperation region. If $U_{l s e t 1}<U_{L 12 \_}<U_{l s e t 2}$ is satisfied, the decision on internal or external fault is taken using $\left|\mathrm{dU}_{d c} / \mathrm{dt}\right|>\mathrm{M}_{\text {set }}$. Here $\mathrm{M}_{\text {set }}$ is the threshold to mitigate the maloperation. The flowchart shown in Fig. 11 shows the proposed protection scheme.

\section{RESUlts AND VALIDATION}

Fig. 1 shows the four-terminal MMC-HVDC system with DC voltage of $\pm 200 \mathrm{kV}$. MMC at bus 1 operates in DC voltage control and constant reactive power control [23]. MMCs at bus 2-4 operate in constant active and reactive power control. The parameters employed for different MMCs are shown in Table III.

TABLE IV: Parameters implemented for different MMCs

\begin{tabular}{|c|c|c|c|c|}
\hline & $\mathrm{MMC}_{1}$ & $\mathrm{MMC}_{2}$ & $\mathrm{MMC}_{3}$ & $\mathrm{MMC}_{4}$ \\
\hline Capacity (MW) & 800 & 1200 & 1600 & 2000 \\
\hline Rated DC Voltage (kV) & \pm 200 & \pm 200 & \pm 200 & \pm 200 \\
\hline Rated Current (kA) & 0.8 & 1.2 & 1.6 & 2 \\
\hline No. of SMs per arm & 200 & 200 & 200 & 200 \\
\hline
\end{tabular}

The different parameters employed in the overall scheme are shown in Table IV. The sampling frequency $\left(\mathrm{f}_{s}\right)$ of the proposed scheme is $20 \mathrm{kHz}$. For the wavelet transform is set as 1-level and the corresponding frequency is $5 \mathrm{kHz}-10 \mathrm{kHz}$ [13]. The mother wavelet is selected as sym8 [15]. Frequency

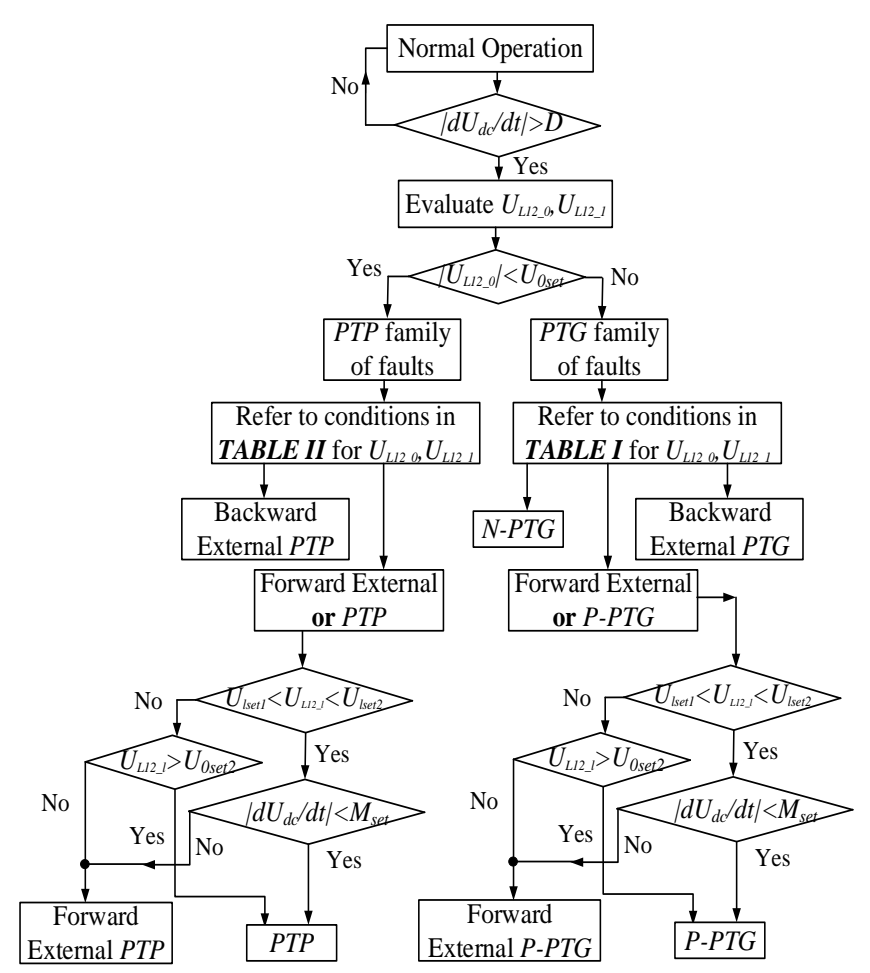

Fig. 11: Flowchart of proposed protection scheme 
dependent (phase) model is used to model overhead transmission line (OHL) with DC correction (refer Appendix). The test system is simulated employing PSCAD/EMTDC based electromagnetic transient simulations.

\section{A. Evaluating trigger event threshold, $D$}

The absolute rate of change of DC voltage, $\left|d U_{d c} / d t\right|$ is used as the trigger event for the evaluation of decisive parameters, $U_{L 12 \_0}$ and $U_{L 12 \_1}$. The threshold for the trigger event, $D$ is defined for a DC fault contingency in the system with the objective that normal system transients should not be identified as a fault. The decision for $D$ is taken considering different type of fault contingencies, PTP and $P T G$, with varying fault location in the OHL and for varying fault resistance, $R_{f}$. As shown in Fig. 12, the magnitude of $\left|d U_{d c} / d t\right|$ decreases with the increase in fault resistance, $\mathrm{R}_{f}$ and the increase in the fault location percentage in a line. Based on the results shown in Fig. 12, $D$ is taken to be $100 \mathrm{kV} / \mathrm{ms}$ keeping a considerable safety margin and timely triggering to avoid delays.

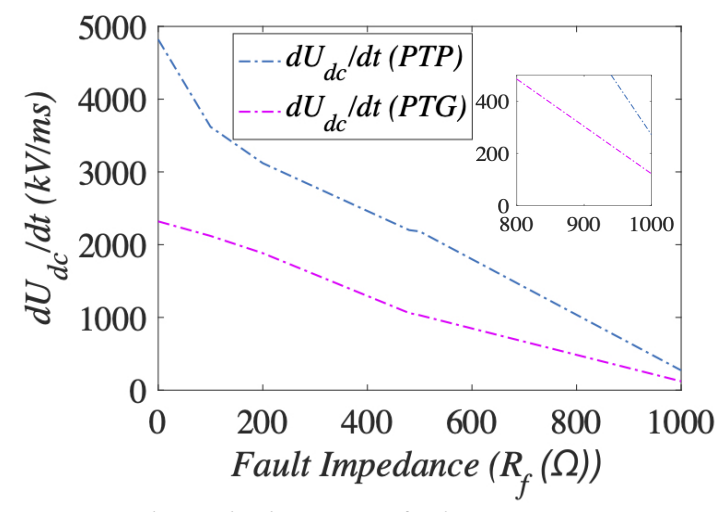

Fig. 12: $d U_{d c} / d t(k V / m s)$ vs fault resistance, $\mathrm{R}_{f}(\Omega)$

\section{B. Sensitivity Analysis}

The decision of other thresholds ( $U_{0 s e t}, U_{l s e t 1}$ and $\left.U_{l s e t 2}\right)$ is made using the logarithmic partial derivative based sensitivity analysis [27]. The function $G(j \omega)$ is the modevoltage, whereas the variables $p_{i}$ are the critical parameters $\left(R_{f}, L_{T m n}\right)$. The sensitivity of function $G(j \omega)$ for a small variation in $p_{i}$ is defined as:

$$
\left.S_{p_{i}}^{G(j \omega) \triangleq} \frac{\partial \ln G(j \omega)}{\partial \ln p_{i}}\right|_{p_{i 0}}=\left.\frac{\frac{\partial \ln G(j \omega)}{G(j \omega)}}{\frac{\partial \ln p_{i}}{p_{i}}}\right|_{p_{i 0}}=\left.\frac{\partial G(j \omega)}{\partial p_{i}}\right|_{p_{i 0}} \frac{p_{i 0}}{G_{0}(j \omega)}
$$

where $p_{i 0}$ represents nominal value of the $i t h$ parameters and $G_{0}(j \omega)$ represents the nominal value of mode-voltage with $p_{i 0}$ parameter. For a small change $\left(\Delta p_{i}\right)$, the modevoltage function is evaluated as:

$$
G\left(j \omega, p_{i}\right)=G\left(j \omega, p_{i 0}\right)+\frac{\Delta p_{i}}{p_{i 0}} S_{p_{i}}^{G(j \omega)}
$$

where $\Delta p_{i}=p_{i}-p_{i 0}$ and for $i=1, \sum_{i=1}^{n} S_{p_{i}}^{G(j \omega)}=S_{p_{1}}^{G(j \omega)}$.
1) Sensitivity with fault resistance, $R_{f}$ : PTP line-mode voltage is considered as the sensitivity function $\left(U_{L 12_{2} l}\right)$. The sensitivity of line-mode voltage with fault resistance is defined as:

$$
\begin{gathered}
S_{R_{f}}^{U_{L 12 l}(j \omega)}=\left.\frac{\partial \ln U_{N}}{\partial \ln R_{f}}\right|_{R_{f 0}}-\left.\frac{\partial \ln U_{D}}{\partial \ln R_{f}}\right|_{R_{f 0}} \\
S_{R_{f}}^{U_{L 12 \_} l(j \omega)}=-\frac{\gamma R_{f 0}}{Z_{1}+\gamma R_{f 0}}
\end{gathered}
$$

where $U_{L 12 \_l}=\frac{U_{N}}{U_{D}}$ and $1+\frac{Z_{1}}{Z_{2}}=\gamma$. For a small change $\left(\Delta R_{f}\right)$, the line-mode voltage, $U_{L 12 \_l}$ is evaluated as:

$$
U_{L 12 \_l}\left(j \omega, R_{f}\right)=U_{L 12_{-} l}\left(j \omega, R_{f 0}\right)-\frac{\gamma \Delta R_{f}}{Z_{1}+\gamma R_{f 0}}
$$

where $\Delta R_{f}=R_{f}-R_{f 0}$. Fig. 16 shows the variation of $U_{L 12 \_l}$ with $R_{f}$. With increasing $\mathrm{R}_{f}$, the signal damping is increasing.
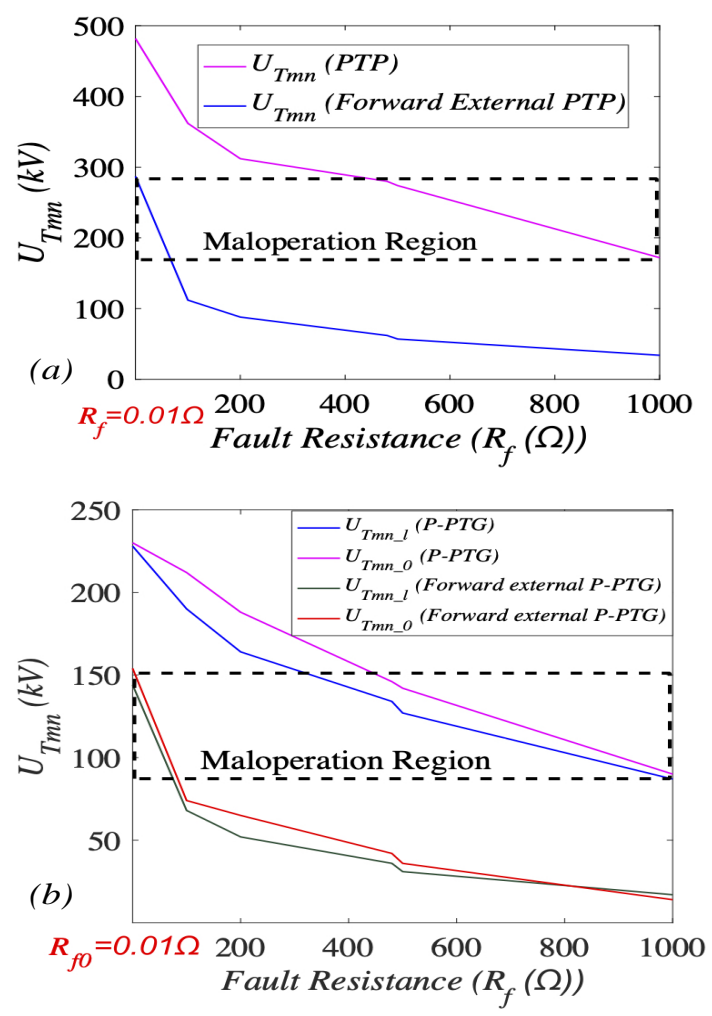

Fig. 13: $U_{T m n}(k V)$ vs $\mathrm{R}_{f}(\Omega)$ for (a) PTP, (b) PTG faults

Fig. 13 shows the variation of mode voltages with fault resistance for different fault contingencies used to define maloperation region. Mode voltage variation with fault resistance follows an inverse relation. This means that when fault resistance increases, mode voltages decrease [refer eq. (20)]. If the thresholds for mode voltages are lower, the scheme may detect higher impedance faults. However, the selectivity can be jeopardised in case of low impedance forward external faults (refer to Fig. 10). The proposed work uses a lower threshold setting keeping in mind the idea to differentiate between a forward external LIF with internal HIF. This makes the proposed scheme sensitive to HIFs up to $1000 \Omega$. 

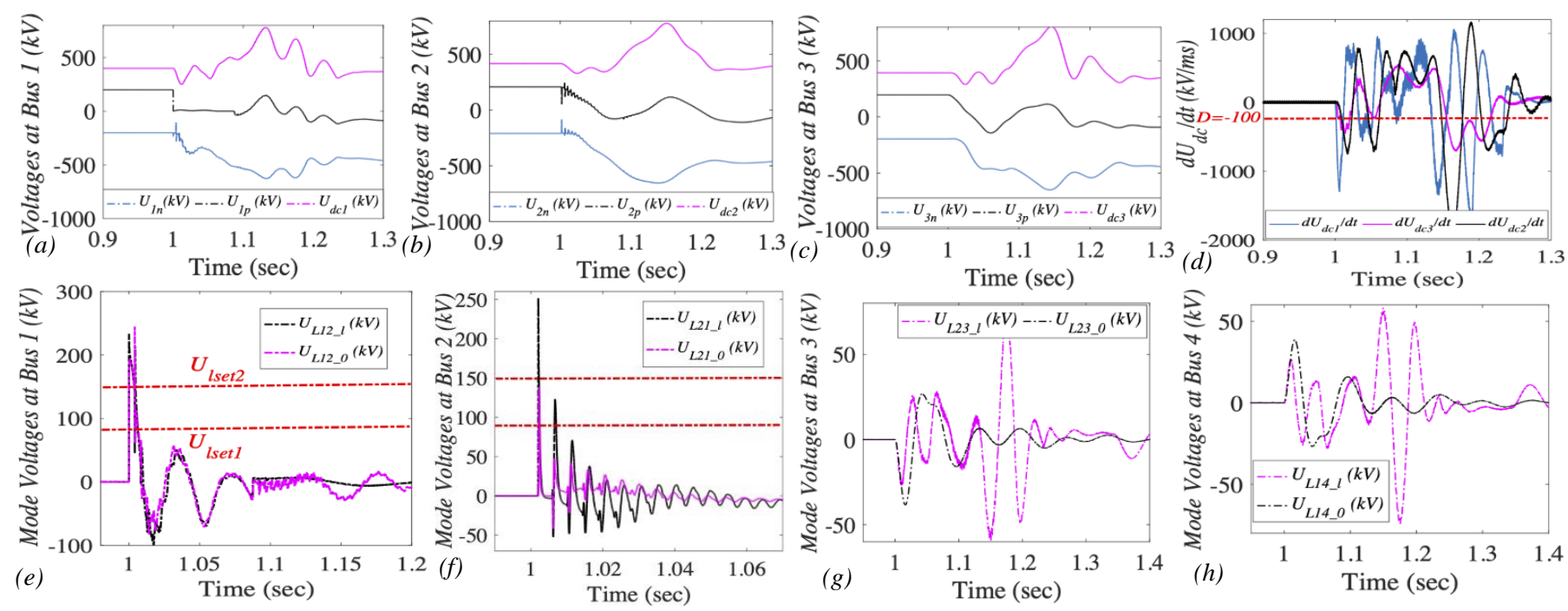

Fig. 14: Simulation results for P-PTG fault at $\mathrm{t}=1 \mathrm{~s}$ for (a) Voltages at bus $1(\mathrm{kV})$ vs Time (sec), (b) Voltages at bus $2(\mathrm{kV})$ vs Time (sec), (c) Voltages at bus $3(\mathrm{kV})$ vs Time (sec), (d) $\mathrm{dU}_{d c} / \mathrm{dt}(\mathrm{kV} / \mathrm{ms})$ vs Time (sec), (e) Mode voltages at Bus 1 (kV) vs Time (sec), (f) Mode voltages at Bus $2(\mathrm{kV})$ vs Time (sec), (g) Mode voltages at Bus $3(\mathrm{kV})$ vs Time (sec), (h) Mode voltages at Bus $4(\mathrm{kV})$ vs Time (sec)

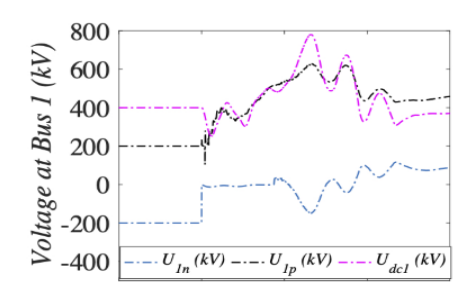

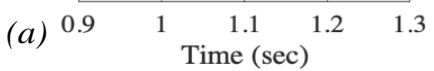

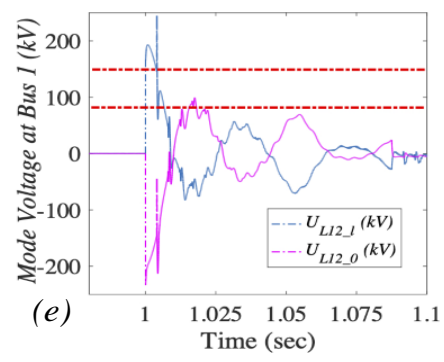

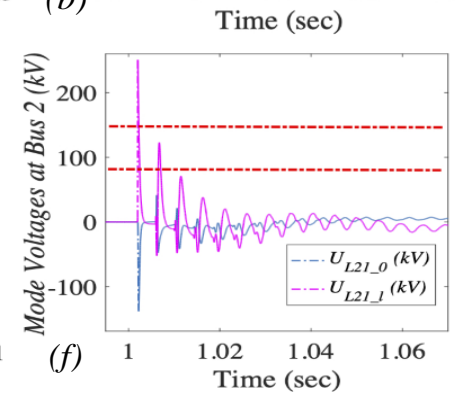
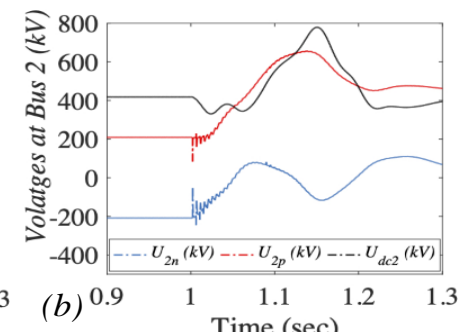
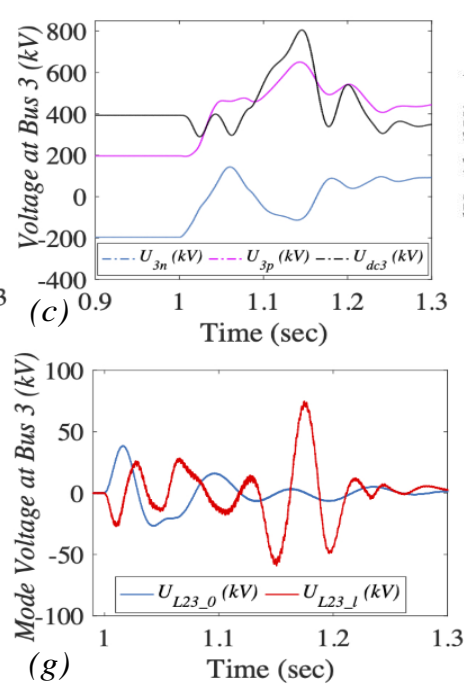
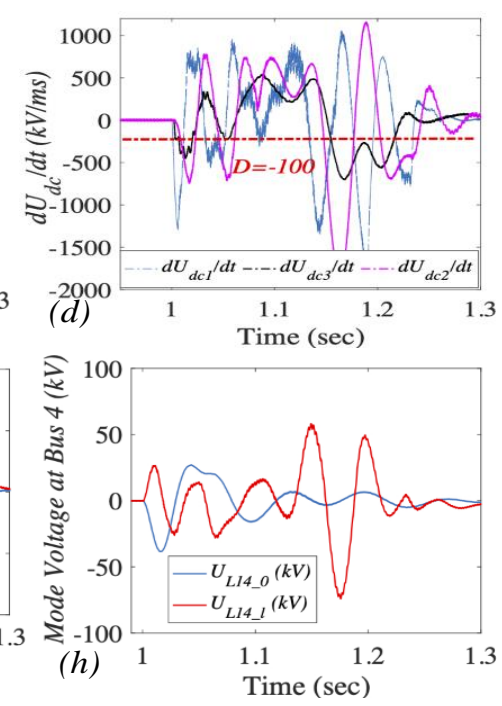

Fig. 15: Simulation results for N-PTG fault at $\mathrm{t}=1 \mathrm{~s}$ for (a) Voltages at bus $1(\mathrm{kV})$ vs Time (sec), (b) Voltages at bus 2 (kV) vs Time (sec), (c) Voltages at bus $3(\mathrm{kV})$ vs Time (sec), (d) $\mathrm{dU}_{d c} / \mathrm{dt}(\mathrm{kV} / \mathrm{ms})$ vs Time (sec), (e) Mode voltages at Bus 1 (kV) vs Time (sec), (f) Mode voltages at Bus $2(\mathrm{kV})$ vs Time (sec), (g) Mode voltages at Bus $3(\mathrm{kV})$ vs Time (sec), (h) Mode voltages at Bus $4(\mathrm{kV})$ vs Time (sec)

2) Sensitivity with current limiting reactor, LTmn: The sensitivity of line-mode voltage with current limiting reactor is defined as:

$$
S_{L_{T 12}}^{U_{L 12 l}=}=\left.\frac{\partial \ln U_{N}}{\partial \ln L_{T 12}}\right|_{L_{T 120}}-\left.\frac{\partial \ln U_{D}}{\partial \ln L_{T 12}}\right|_{L_{T 120}}
$$

The sensitivity function is simplified to:

$$
S_{L_{T 12}}^{U_{L 12 l}=1-2 j \omega \frac{\left(1+\beta^{2}\right) L_{T 120}}{Z_{1}+\gamma R_{f}}}
$$

where $\beta=\frac{L_{M M C}}{2 L_{T 12}+L_{M M C}}$ For a small change $\left(\Delta \mathrm{L}_{T 12}\right)$, the linemode voltage, $U_{L 12 \_} l$ is evaluated as:

$$
\begin{aligned}
& U_{L 12 \_l}\left(j \omega, L_{T 12}\right)=U_{L 12 \_l}\left(j \omega, L_{T 120}\right) \\
& -\Delta L_{T 12}\left(\frac{1}{L_{T 120}}-\frac{2 j \omega\left(1+\beta^{2}\right)}{Z_{1}+\gamma R_{f}}\right)
\end{aligned}
$$

where $\Delta L_{T 12}=L_{T 12}-L_{T 120}$. Fig. 16 shows the variation of mode voltages with value of CLR.

\section{Scheme validation for different faults}

1) Validation for P-PTG faults: A metallic P-PTG fault $\left(\mathrm{F}_{1}\right.$ in Fig. 1) occurs at $\mathrm{t}=1 \mathrm{~s}$ at a distance of $50 \%$ in Line 1. The decisive parameters are analysed in Fig. 14. Fig. 14(a) shows DC link voltage at bus $1\left(U_{d c 1}\right)$, positive pole voltage $\left(U_{1 p}\right)$ and negative pole voltage $\left(U_{1 n}\right)$. Fig. 14(b) shows $U_{d c 2}, U_{2 p}$ and $U_{2 n}$ and Fig. 14(c) shows $U_{d c 3}, U_{3 p}$ and $U_{3 n}$. 
TABLE V: Variation of mode voltages at different CLRs with variation of fault location (internal- $F_{1}$, external- $F_{2}$ ) and fault resistance

\begin{tabular}{|c|c|c|c|c|c|c|c|c|c|c|c|c|c|c|c|c|c|c|c|c|c|c|c|c|}
\hline & \multicolumn{8}{|c|}{$R=0.01 \Omega$} & \multicolumn{8}{|c|}{$R=0.35 \Omega$} & \multicolumn{8}{|c|}{$R=3.1 \Omega$} \\
\hline & \multicolumn{2}{|c|}{$U_{L 12}(k V)$} & \multicolumn{2}{|c|}{$U_{L 21}(k V)$} & \multicolumn{2}{|c|}{$U_{L 14}(k V)$} & \multicolumn{2}{|c|}{$U_{L 23}(k V)$} & \multicolumn{2}{|c|}{$U_{L 12}(k V)$} & \multicolumn{2}{|c|}{$U_{L 21}(k V)$} & \multicolumn{2}{|c|}{$U_{L 14}(k V)$} & \multicolumn{2}{|c|}{$U_{L 23}(k V)$} & \multicolumn{2}{|c|}{$U_{L 12^{(k V)}}$} & \multicolumn{2}{|c|}{$U_{L 21}(k V)$} & \multicolumn{2}{|c|}{$U_{L 14}(k V)$} & \multicolumn{2}{|c|}{$U_{L 23}(k V)$} \\
\hline & Zero & Line & Zero & Line & Zero & Line & Zero & Line & Zero & Line & Zero & Line & Zero & Line & Zero & Line & Zero & Line & Zero & Line & Zero & Line & Zero & Line \\
\hline \multicolumn{25}{|l|}{$P$-PTG } \\
\hline $10 \%$ & 227.3 & 180.3 & 190.4 & 172.4 & 43.2 & 38.4 & -42.2 & -38.7 & 220.4 & 173.5 & 182.2 & 163.4 & 41.2 & 35.6 & -39.8 & -36.8 & 115.6 & 108.6 & 110.4 & 166.6 & 28.7 & 26.5 & -26.4 & -23.4 \\
\hline $30 \%$ & 234.2 & 204.2 & 198.2 & 176.5 & 47.2 & 41.2 & -45.2 & -39.4 & 227.8 & 196.8 & 190.4 & 168.8 & 42.6 & 39.8 & -41.6 & -34.6 & 116.6 & 98.4 & 99.4 & 94.5 & 32.4 & 29.8 & -29.8 & -28.8 \\
\hline $50 \%$ & 221.6 & 188.8 & 176.2 & 164.2 & 44.4 & 40.2 & -38.2 & -36.7 & 214.5 & 180.2 & 169.8 & 158.5 & 41.4 & 38.7 & -34.5 & -34.1 & 110.6 & 99.6 & 104.6 & 97.8 & 28.4 & 23.5 & -27.3 & -22.4 \\
\hline $70 \%$ & 232.4 & 198.5 & 188.4 & 162.4 & 47.8 & 43.2 & -42.5 & -40.1 & 222.4 & 201.2 & 192.4 & 173.5 & 42.5 & 38.6 & -34.1 & -29.8 & 124.4 & 112.2 & 114.8 & 104.6 & 35.6 & 30.6 & -33.4 & -28.8 \\
\hline $90 \%$ & 245.2 & 212.2 & 198.2 & 178.2 & 45.6 & 39.8 & -38.1 & -32.8 & 237.4 & 202.4 & 190.2 & 173.4 & 41.5 & 35.6 & -31.2 & -27.8 & 138.6 & 120.4 & 106.4 & 96.4 & 32.4 & 26.8 & -36.8 & -30.2 \\
\hline External & 144.2 & 120.3 & -212.1 & -202.2 & 142.6 & 120.8 & -207.6 & -212.4 & 137.2 & 115.1 & -201.6 & -192.3 & 136.8 & 113.4 & -198.8 & -201.2 & 90.2 & 82.4 & -80.2 & -76.2 & 90.4 & 88.6 & -84.2 & -78.6 \\
\hline \multicolumn{25}{|l|}{$N-P T G$} \\
\hline $10 \%$ & -227.3 & 180.1 & -190.4 & 172.3 & 43.2 & 38.4 & -42.2 & -38.7 & -220.4 & 173.5 & -182.2 & 163.4 & 41.2 & 35.6 & -39.8 & -36.8 & -115.6 & 108.6 & -110.4 & 166.6 & 28.7 & 26.5 & -26.4 & -23.4 \\
\hline $30 \%$ & -234.2 & 204.2 & -198.2 & 176.5 & 47.2 & 41.2 & -45.2 & -39.4 & -227.8 & 196.8 & -190.4 & 168.8 & 42.6 & 39.8 & -41.6 & -34.6 & -116.6 & 98.4 & -99.4 & 94.5 & 32.4 & 29.8 & -29.8 & -28.8 \\
\hline $50 \%$ & -221.6 & 188.8 & -176.2 & 164.2 & 44.4 & 40.2 & -38.2 & -36.7 & -214.5 & 180.2 & -169.8 & 158.5 & 41.4 & 38.7 & -34.5 & -34.1 & -110.6 & 99.6 & -104.6 & 97.8 & 28.4 & 23.5 & -27.3 & -22.4 \\
\hline $70 \%$ & -232.4 & 198.5 & -188.4 & 162.4 & 47.8 & 43.2 & -42.5 & -40.1 & -222.4 & 201.2 & -192.4 & 173.5 & 42.5 & 38.6 & -34.1 & -29.8 & -124.4 & 112.2 & -114.8 & 104.6 & 35.6 & 30.6 & -33.4 & -28.8 \\
\hline $90 \%$ & -245.2 & 212.2 & -198.2 & 178.2 & 45.6 & 39.8 & -38.1 & -32.8 & -237.4 & 202.4 & -190.2 & 173.4 & 41.5 & 35.6 & -31.2 & -27.8 & -138.6 & 120.4 & -106.4 & 96.4 & 32.4 & 26.8 & -36.8 & -30.2 \\
\hline $\begin{array}{l}\text { External } \\
\qquad P T P\end{array}$ & -144.2 & 120.3 & -212.1 & -202.2 & -142.6 & 120.8 & -207.6 & -212.4 & -137.2 & 115.1 & -201.6 & -192.3 & -138.8 & 113.4 & -198.8 & -201.2 & -90.2 & 82.4 & -80.2 & -76.2 & -90.4 & 88.6 & -84.2 & -78.6 \\
\hline $10 \%$ & 0.1 & 482.2 & 0.2 & 441.4 & 0.2 & 80.4 & -0.2 & -76.7 & 0.2 & 473.2 & 0.1 & 432.6 & 0.2 & 75.6 & -0.4 & -70.8 & 0.6 & 378.6 & 0.2 & 326.8 & 0.3 & 42.3 & -0.3 & -34.2 \\
\hline $30 \%$ & 0.2 & 462.4 & 0.3 & 446.4 & 0.3 & 82.4 & -0.3 & -74.2 & 0.3 & 456.8 & 0.4 & 440.6 & 0.2 & 77.8 & -0.4 & -74.3 & 0.7 & 346.6 & 0.4 & 332.4 & 0.3 & 52.6 & -0.5 & -46.8 \\
\hline $50 \%$ & 0.2 & 446.5 & 0.2 & 427.4 & 0.3 & 74.2 & -0.2 & -71.2 & 0.2 & 440.2 & 0.3 & 420.6 & 0.1 & 70.2 & -0.3 & -66.6 & 0.1 & 336.6 & 0.3 & 312.6 & 0.2 & 47.2 & -0.4 & -45.2 \\
\hline $70 \%$ & 0.3 & 461.4 & 0.1 & 433.6 & 0.1 & 87.6 & -0.1 & -78.2 & 0.1 & 453.6 & 0.3 & 423.7 & 0.3 & 81.5 & -0.2 & -72.2 & 0.3 & 348.6 & 0.3 & 318.2 & 0.4 & 54.6 & -0.4 & -45.7 \\
\hline $90 \%$ & 0.1 & 472.6 & 0.2 & 439.8 & 0.2 & 88.2 & -0.3 & -80.2 & 0.4 & 465.6 & 0.3 & 428.4 & 0.1 & 83.2 & -0.2 & -74.3 & 0.1 & 368 & 0.2 & 354.4 & 0.2 & 52.6 & -0.3 & -48.6 \\
\hline External & 0.1 & 287.8 & -0.3 & -305 & 0.2 & 288.4 & -0.2 & -327 & 0.1 & 280.3 & -0.2 & -293.2 & 0.2 & 282.4 & -0.4 & -275.4 & 0.2 & 178.1 & -0.2 & -214 & -0.3 & 179.2 & -0.2 & -234.5 \\
\hline
\end{tabular}

\begin{tabular}{|c|c|c|c|c|c|c|c|c|c|c|c|c|c|c|c|c|c|c|c|c|c|c|c|c|}
\hline & \multicolumn{8}{|c|}{$R=480 \Omega$} & \multicolumn{8}{|c|}{$R=500 \Omega$} & \multicolumn{8}{|c|}{$R=1000 \Omega$} \\
\hline & \multicolumn{2}{|c|}{$U_{L 12}(k V)$} & \multicolumn{2}{|c|}{$U_{L 21}(k V)$} & \multicolumn{2}{|c|}{$U_{L 14}(k V)$} & \multicolumn{2}{|c|}{$U_{L 23}(k V)$} & \multicolumn{2}{|c|}{$U_{L 12}(k V)$} & \multicolumn{2}{|c|}{$U_{L 21}(k V)$} & \multicolumn{2}{|c|}{$U_{L 14}(k V)$} & \multicolumn{2}{|c|}{$U_{L 23}(k V)$} & \multicolumn{2}{|c|}{$U_{L 12}(k V)$} & \multicolumn{2}{|c|}{$U_{L 21}(k V)$} & \multicolumn{2}{|c|}{$U_{L 14}(k V)$} & \multicolumn{2}{|c|}{$U_{L 23}(k V)$} \\
\hline & Zero & Line & Zero & Line & Zero & Line & Zero & Line & Zero & Line & Zero & Line & Zero & Line & Zero & Line & Zero & Line & Zero & Line & Zero & Line & Zero & Line \\
\hline \multicolumn{25}{|l|}{ P-PTG } \\
\hline $10 \%$ & 143.2 & 120.5 & 138.8 & 114.6 & 20.2 & 18.6 & -19.8 & -18.7 & 135.2 & 133.5 & 142.2 & 133.4 & 36.6 & 33.3 & -33.8 & -31.8 & 90.2 & 84.4 & 91.4 & 86.6 & 10.7 & 10.5 & -12.4 & -11.4 \\
\hline $30 \%$ & 142.2 & 126.2 & 140.2 & 96.5 & 25.2 & 24.6 & -22.2 & -18.8 & 139.6 & 134.6 & 142.4 & 138.8 & 22.5 & 19.9 & -21.6 & -18.7 & 91.4 & 82.2 & 92.4 & 87.3 & 12.4 & 9.8 & -9.8 & -8.8 \\
\hline $50 \%$ & 141.6 & 128.8 & 146.6 & 124.8 & 23.4 & 20.6 & -18.8 & -16.7 & 137.5 & 130.2 & 139.8 & 128.5 & 36.4 & 36.7 & -32.5 & -31.1 & 89.6 & 81.3 & 90.1 & 86.2 & 10.4 & 10.5 & -12.3 & -10.4 \\
\hline $70 \%$ & 144.8 & 138.6 & 142.4 & 122.4 & 22.8 & 20.2 & -20.5 & -18.1 & 136.4 & 131.2 & 142.4 & 128.5 & 25.5 & 22.6 & -28.1 & -21.8 & 90.4 & 82.2 & 91.2 & 87.6 & 11.6 & 10.6 & -13.4 & -11.8 \\
\hline $90 \%$ & 145.5 & 132.2 & 148.2 & 128.2 & 26.6 & 19.8 & -21.1 & -18.8 & 138.6 & 132.4 & 138.2 & 123.4 & 41.5 & 35.6 & -31.2 & -27.8 & 91.4 & 84.4 & 92.4 & 89.1 & 12.2 & 11.8 & -12.8 & -11.2 \\
\hline External & 70.6 & 66.4 & -104.2 & -93.2 & 72.6 & 68.8 & -107.4 & -102.4 & 67.2 & 60.1 & -110.6 & -98.4 & 74.2 & 67.5 & -118.8 & -101.5 & 12.1 & 10.4 & -11.2 & -10.2 & 13.4 & 12.6 & -12.2 & -11.6 \\
\hline \multicolumn{25}{|l|}{$N$-PTG } \\
\hline $10 \%$ & -143.2 & 120.5 & -138.8 & 114.6 & 20.2 & 18.6 & -19.8 & -18.7 & -135.2 & 133.5 & -142.2 & 133.4 & 36.6 & 33.3 & -33.8 & -31.8 & -90.2 & 84.4 & -91.4 & 86.6 & 10.7 & 10.5 & -12.4 & -11.4 \\
\hline $30 \%$ & -142.2 & 126.2 & -140.2 & 96.5 & 25.2 & 24.6 & -22.2 & -18.8 & -139.6 & 134.6 & -142.4 & 138.8 & 22.5 & 19.9 & -21.6 & -18.7 & -91.4 & 82.2 & -92.4 & 87.3 & 12.4 & 9.8 & -9.8 & -8.8 \\
\hline $50 \%$ & -141.6 & 128.8 & -146.6 & 124.8 & 23.4 & 20.6 & -18.8 & -16.7 & -137.5 & 130.2 & -139.8 & 128.5 & 36.4 & 36.7 & -32.5 & -31.1 & -89.6 & 81.3 & -90.1 & 86.2 & 10.4 & 10.5 & -12.3 & -10.4 \\
\hline $70 \%$ & -144.8 & 138.6 & -142.4 & 122.4 & 22.8 & 20.2 & -20.5 & -18.1 & -136.4 & 131.2 & -142.4 & 128.5 & 25.5 & 22.6 & -28.1 & -21.8 & -90.4 & 82.2 & -91.2 & 87.6 & 11.6 & 10.6 & -13.4 & -11.8 \\
\hline $90 \%$ & -145.5 & 132.2 & -148.2 & 128.2 & 26.6 & 19.8 & -21.1 & -18.8 & -138.6 & 132.4 & -138.2 & 123.4 & 41.5 & 35.6 & -31.2 & -27.8 & -91.4 & 84.4 & -92.4 & 89.1 & 12.2 & 11.8 & -12.8 & -11.2 \\
\hline External & -70.6 & 66.4 & -104.2 & -93.2 & -72.6 & 68.8 & -107.4 & -102.4 & -67.2 & 60.1 & -110.6 & -98.4 & -74.2 & 67.5 & -118.8 & -101.5 & -12.1 & 10.4 & -11.2 & -10.2 & -13.4 & 12.6 & -12.2 & -11.6 \\
\hline \multicolumn{25}{|l|}{$P T P$} \\
\hline $10 \%$ & 0.1 & 285.8 & 0.2 & 292.2 & 0.2 & 42.4 & -0.2 & -46.7 & 0.3 & 278.5 & 0.2 & 283.2 & 0.6 & 38.2 & -0.2 & -40.8 & 0.4 & 176.6 & 0.3 & 177.8 & 0.3 & 18.3 & -0.2 & -14.3 \\
\hline $30 \%$ & 0.3 & 287.8 & 0.2 & 290.4 & 0.3 & $\begin{array}{l}42.2 \\
\end{array}$ & -0.3 & -44.2 & 0.3 & 279.6 & 0.2 & 285.2 & 0.8 & 37.2 & -0.3 & $\begin{array}{l}-39.2 \\
-39.2\end{array}$ & 0.2 & 177.4 & 0.3 & 179.2 & 0.6 & 16.3 & -0.8 & -18.5 \\
\hline $50 \%$ & 0.4 & 286.2 & 0.3 & 287.8 & 0.2 & 41.5 & -0.2 & -40.3 & 0.2 & 278.8 & 0.3 & 281.6 & 0.2 & 37.2 & -0.6 & -38.4 & 0.3 & 176.2 & 0.3 & 177.1 & 0.2 & 17.6 & -0.2 & -15.2 \\
\hline $70 \%$ & 0.5 & 289.5 & 0.2 & 288.8 & 0.1 & 45.6 & -0.2 & -39.1 & 0.2 & 281.2 & 0.4 & 280.4 & 0.5 & 41.5 & -0.2 & -36.4 & 0.3 & 179.1 & 0.3 & 177.2 & 0.6 & 14.2 & -0.2 & -15.2 \\
\hline $90 \%$ & 0.1 & 292.2 & 0.3 & 288.2 & 0.2 & 41.2 & -0.2 & -42.3 & 0.2 & 284.2 & 0.4 & 282.4 & 0.2 & 41.1 & -0.3 & -39.4 & 0.3 & 178.9 & 0.3 & 179.3 & 0.6 & 18.2 & -0.6 & -18.3 \\
\hline External & 0.3 & 132.8 & -0.5 & -162 & 0.4 & 132.4 & -0.2 & -162 & 0.2 & 125.2 & -0.4 & -128.2 & 0.3 & 127.4 & -0.4 & -122.4 & 0.1 & 38.1 & -0.2 & 24.7 & 0.3 & 29.2 & -0.2 & -35.4 \\
\hline
\end{tabular}

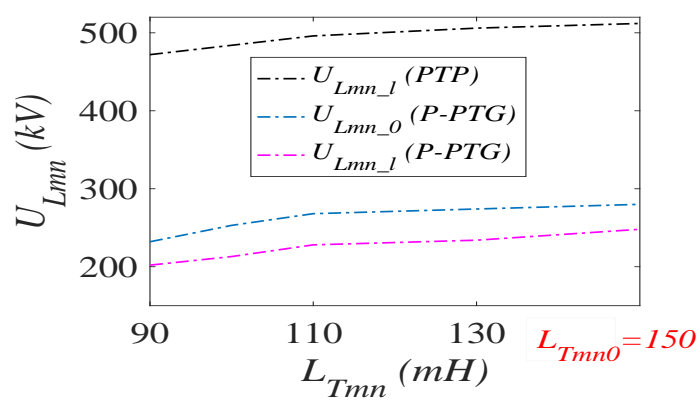

Fig. 16: $U_{T m n}(k V)$ vs $\mathrm{L}_{T m n}(\mathrm{mH})$

Fig. 14(d) shows that $\left|d U_{d c} / d t\right|>D$ for bus 1-3. This triggers the evaluation of $U_{L m n_{-} l}$ and $U_{L m n_{-} 0}$. Since $\left|U_{L m n_{-} 0}\right|>U_{0 s e t}$, the fault is identified as PTG family of faults. For bus 1-2, $U_{L 12 \_}>U_{l s e t 2}$, the fault is identified as internal as shown in Fig. 14(e), (f). For bus 3, the fault is identified as backward external P-PTG while for bus 4 , the fault is identified as forward external P-PTG as shown in Fig. 14(g), (h).

2) Validation for N-PTG faults: Similar to previous subsection (P-PTG), Fig. 15 shows the fault identification for a N-PTG metallic fault at $\mathrm{t}=1 \mathrm{~s}$ at a distance of $50 \%$.

3) Validation for PTP faults: Fig. 18 shows the fault identification for a PTP fault considering the effect of power reversal on the scheme (Refer to Section VI $(G)$ ).

\section{Analysing maloperation region}

As shown in Fig. 10 and Fig. 13, line mode voltage $\left(\mathrm{U}_{L m n_{-} l}\right)$ as the decisive parameter for tripping can lead $\mathrm{U}_{L 12 \_l}$ generate a trip signal for the fault $\mathrm{F}_{2}$ (Forward external fault). This maloperation region is defined with thresholds $U_{l \text { lset } 1}$ and $U_{\text {lset } 2 \text {. The analysis is sensitive to }}$ HIFs as high as $1000 \Omega$. Table VI shows variation of mode voltages at different CLRs with varying fault distance and fault resistance. Here, external fault is defined as $F_{2}$ in Fig. 1. It is seen that the mode voltages for external LIFs and internal HIFs are in range to each other (refer to bold numbers in Table V). As a result of which, maloperation region is formed $\left(170 \mathrm{kV}<U_{L 12 \_}<300 \mathrm{kV}\right.$ for PTP and $85 k V<U_{L 12 \_} l<150 k V$ for PTG) where a forward external fault can lead to selectivity problems for the scheme. Hence if $U_{l \text { set } 1}<U_{L 12_{-} l}<U_{l \text { set } 2}, d U_{d c} / d t$ is used as the decisive parameter to decide between Forward External or internal HIF as shown in Table VI. Table VI shows $d U_{d c} / d t$ for HIFs at a fault distance of $10 \%$. This gives the maximum possible value of $d U_{d c} / d t$ for HIFs. The threshold $M_{s e t}$ is defined as $-3000 \mathrm{kV} / \mathrm{ms}$ for PTP and $-1500 \mathrm{kV} / \mathrm{ms}$ for PTG faults.

\section{E. Fault Detection Time}

Detection time is a result of delay of propagation time of travelling waves and delay to violate the triggering event. 
TABLE VI: Analysis of Maloperation region

\begin{tabular}{rrrrrrr}
\hline \multicolumn{7}{c}{ Fault Resistance $(\Omega)$} \\
\hline$\frac{d U_{d c}}{d t}(\boldsymbol{k V} / \boldsymbol{m} \boldsymbol{s})$ & \multicolumn{3}{c}{ Forward External } & \multicolumn{3}{c}{ High Impedance Internal } \\
\hline $\boldsymbol{P T P}$ & $0.01 \Omega$ & $0.35 \Omega$ & $3.1 \Omega$ & $480 \Omega$ & $500 \Omega$ & $1000 \Omega$ \\
\hline$\frac{d U_{d c 1}}{d t}$ & -4962 & -4896 & -4688 & -2022 & -1988 & -212 \\
\hline$\frac{d U_{d c 2}}{d t}$ & -5024 & -5054 & -4921 & -1968 & -1937 & -184 \\
\hline $\boldsymbol{P T G}$ & $0.01 \Omega$ & $0.35 \Omega$ & $3.1 \Omega$ & $480 \Omega$ & $500 \Omega$ & $1000 \Omega$ \\
\hline$\frac{d U_{d c 1}}{d t}$ & -2464 & -2412 & -2310 & -1267 & -1212 & -122 \\
\hline$\frac{d U_{d c 2}}{d t}$ & -2668 & -2611 & -2516 & -1313 & -1245 & -118 \\
\hline
\end{tabular}

Fig. 10 shows the zoomed propagation time of the waves for 2 fault scenarios. One at $10 \%$, other at $100 \%$ (forward external). This is the case with maximum propagation delay in the analysis. The proposed fault identification scheme considers HIF up to $1000 \Omega$ which delays $\left|d U_{d c} / d t\right|>D$. As a result of which the maximum delay encountered or the maximum detection time of the proposed scheme is $2.37 \mathrm{~ms}$.

TABLE VII: Fault Detection Time for the proposed scheme

\begin{tabular}{|c|c|}
\hline Maximum Propagation time of travelling wave & $1.12 \mathrm{~ms}$ \\
\hline Delay for HIF $(1000 \Omega)$ to violate triggering event & $1.13 \mathrm{~ms}$ \\
\hline Delay due to 1-level wavelet transform & $0.12 \mathrm{~ms}$ \\
\hline Maximum delay encountered & $2.37 m s$ \\
\hline
\end{tabular}

\section{F. Response to AC faults}

To check the response of AC faults on the proposed scheme, a $3 \phi$ metallic AC fault is simulated on the AC side of $\mathrm{MMC}_{1}$. The decisive parameters are shown in Fig. 17. $\left|d U_{d c} / d t\right|>D$ is violated for both bus 1-2. However, mode voltages point to no fault zone $\left(U_{L 12 \_l}=-324 \mathrm{kV}\right.$, $\left.U_{L 12 \_0}=186 \mathrm{kV} ; U_{L 21 \_l}=-86 \mathrm{kV}, U_{L 21 \_0}=0.3 \mathrm{kV}\right)$ as can be seen in Fig. 9.
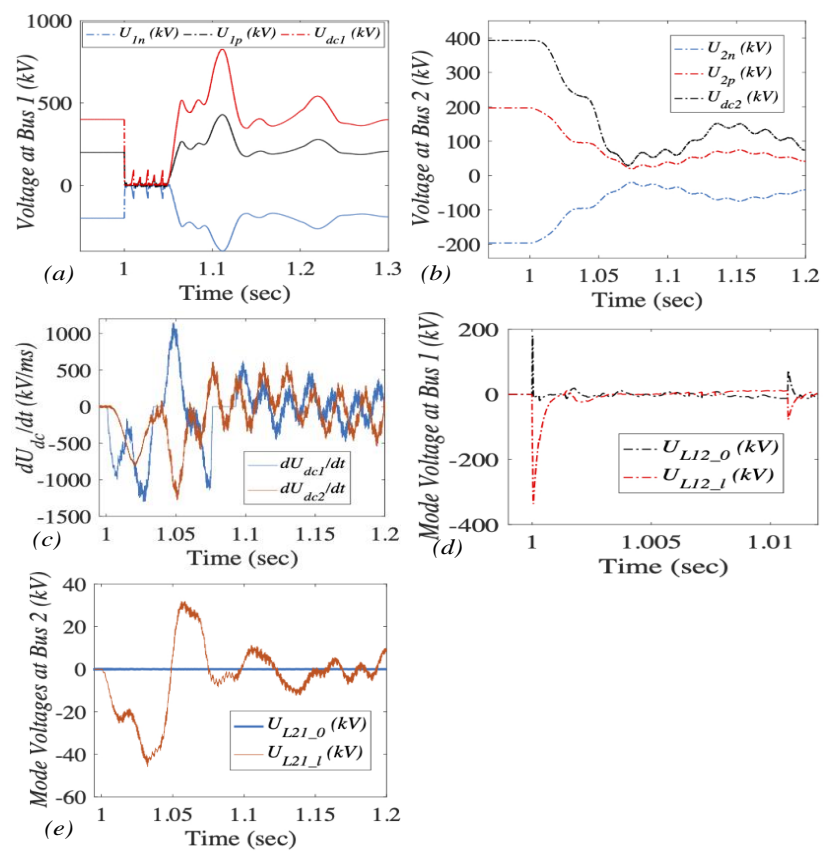

Fig. 17: Simulation results for $\mathrm{AC}$ fault behind $\mathrm{MMC}_{1}$ for (a) Voltage at Bus $1(\mathrm{kV})$ vs Time (sec), (b) Voltage at Bus $2(\mathrm{kV})$ vs Time (sec), (c) $\mathrm{dU}_{d c} / \mathrm{dt}(\mathrm{kV} / \mathrm{ms})$, (d) Mode Voltages at Bus $1(\mathrm{kV})$ vs Time (sec), (e) Mode Voltages at Bus $2(\mathrm{kV})$ vs Time (sec)

\section{G. Response to power reversal}

To check the performance of the scheme under system transients, the $P_{\text {ref }}$ command at each bus is changed at $\mathrm{t}=0.75 \mathrm{~s}$ ( $\mathrm{P}_{1}$ from 0 to $+368 \mathrm{MW}, \mathrm{P}_{2}$ from $+374 \mathrm{MW}$ to $+214 \mathrm{MW}, \mathrm{P}_{3}$ from $+178 \mathrm{MW}$ to $\left.-198 \mathrm{MW}\right)$. As evident from Fig. 18, $\left|\mathrm{d}_{U_{d c}} / \mathrm{dt}\right|<\mathrm{D}$. Since the trigger event is not violated, the performance of the scheme is intact for power reversal and system transients. Following the event of power reversal, a PTP fault is applied at $\mathrm{t}=1 \mathrm{~s}$. As evident from Fig. $18,\left|\mathrm{~d}_{U_{d c}} / \mathrm{dt}\right|>\mathrm{D}$ within $\mathrm{t}=1.001 \mathrm{~s}$. The mode voltage analysis identifies a PTP fault.
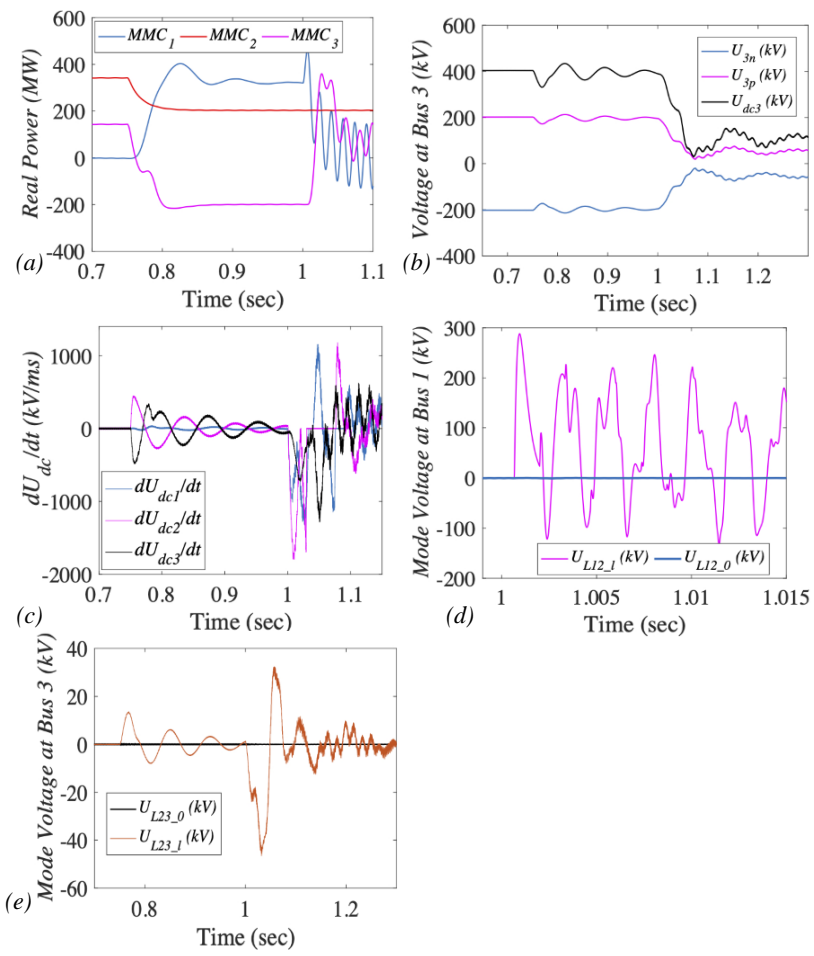

Fig. 18: Simulation results for transient operation in the system (a) Real Power (P) (MW) vs Time (sec), (b) Voltage at Bus $1(\mathrm{kV})$ vs Time (sec), (c) Voltage at Bus $3(\mathrm{kV})$ vs Time (sec), (d) $\mathrm{dU}_{d c} / \mathrm{dt}(\mathrm{kV} / \mathrm{ms})$, (e) Mode Voltage at Bus $1(\mathrm{kV})$ vs Time (sec), (f) Mode voltages at Bus $3(\mathrm{kV})$ vs Time (sec)

\section{H. Response to DCCB operation}

The scheme operation is analysed for a fault $F_{1}$ (Fig. 1). Once, the fault is identified, DCCB operation isolate Line 1. The external mode voltages are analysed for the DCCB operation at $t=1.003 \mathrm{~ms}$ in Fig. 19. It is seen that the external mode voltages do not violate $U_{l s e t 1}$.

\section{Effect of White Gaussian Noise (WGN)}

White Gaussian Noise (WGN) in the measurement induces high frequency components in the measured data of current and voltage. This can cause inaccuracy in the results for the fault identification of the proposed scheme. As a result, a rolling mean filter (RMT) is employed with a moving window of 50 sample steps [16]. WGN is random in nature with the property of zero mean [14]. Hence, the filter eliminates the effect of WGN to a great extent without 


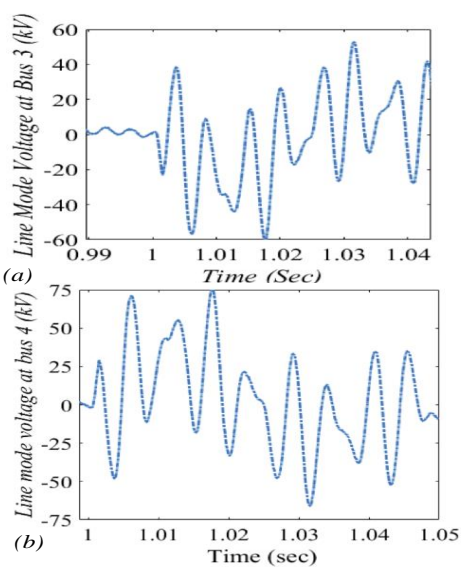

Fig. 19: (a) $\mathrm{U}_{L 23 \_l}(\mathrm{kV})$ vs $\mathrm{T}$ (sec), (b) $\mathrm{U}_{L 14 \_l}(\mathrm{kV})$ vs $\mathrm{T}$ (sec)

affecting the accuracy of the proposed fault identification scheme. Fig. 20(a) shows $U_{d c 1}$ with 30dB WGN and also with RMT. Fig. 20(b) shows $d U_{d c 1} / d t$ obtained through the filtered voltage, $U_{d c 1}$.
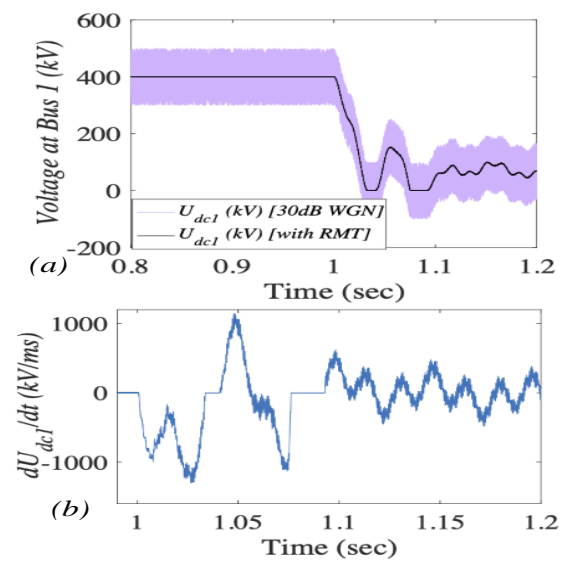

Fig. 20: $\mathrm{U}_{d c 1}$ vs $\mathrm{T}$ (sec), (b) $\mathrm{dU}_{d c 1} / \mathrm{dt}(\mathrm{kV} / \mathrm{ms})$ vs $\mathrm{T}$ (sec)

\section{J. Comparison to relevant literature}

The authors in [14] propose a fast and simple scheme which works up to a fault resistance of $200 \Omega$. Table V shows the existence of maloperation region as the fault resistance increases further. It means scheme in [14] maloperates as fault resistance increases beyond $200 \Omega$. The proposed work studies the effect of fault resistance in the mathematical analysis to increase the reliability of the scheme for HIFs as high as $1000 \Omega$.

The detection time of the proposed scheme is higher than that of in [14]. This is a result of delay due to HIF to violate the triggering event and the delay due to 1-level wavelet transform.

\section{CONCLUSION}

The contribution of the proposed work has been to improve the selectivity (distinguishability between external and internal faults) of localised protection for DC fault identification in multi-terminal MMC-HVDC systems. Based on the findings of the proposed work, it can be concluded that:
- Considering fault resistance in the modal analysis points out the issue of maloperation region for internal high impedance faults (HIFs) and forward external low impedance faults (LIFs).

- Mitigating the region helps the scheme to detect HIF as high as $1000 \Omega$.

- A sensitivity analysis is proposed which formulates the variation of decisive parameters i.e., line-mode and zero-mode voltages with respect to critical parameters like fault resistance and current limiting reactor. This analysis is used to decide system thresholds $\left(U_{0 s e t}\right.$, $U_{l s e t 1}$ and $\left.U_{l s e t 2}\right)$.

- The proposed scheme works well for HIFs, in the presence of WGN up to $30 \mathrm{~dB}$. The scheme is rapid due to localised nature and can identify fault well within $2.4 \mathrm{~ms}$. It is secure for AC faults, DCCB operation, power reversal (load variations).

\section{APPENDIX}

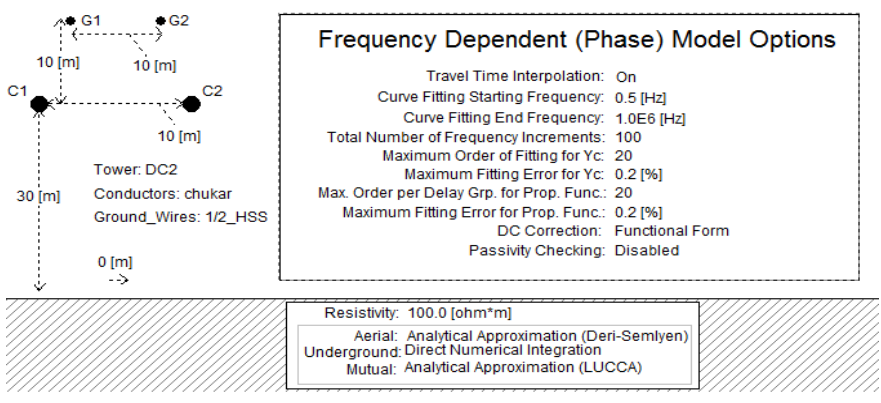

Fig. 21: Implemented overhead Line (OHL) Configuration

\section{REFERENCES}

[1] North Sea Wind Power Hub - Consortium Partners. (2019) Power hub as an island. [Online]. https://northseawindpowerhub.eu/wpcontent/uploads/2019/07/NSWPH-Benefit-study-for-potentiallocations-of-an-offshore-hub-island-1.pdf

[2] A. Orths, A. Hiorns, R. van Houtert, L. Fisher, and C. Fourment, "The european north seas countries' offshore grid initiative-the way forward," in 2012 IEEE Power and Energy Society General Meeting, July 2012, pp. 1-8.

[3] Y. Li et al., "DC Fault Detection in MTDC Systems Based on Transient High Frequency of Current," in IEEE Transactions on Power Delivery, vol. 34, no. 3, pp. 950-962, June 2019, doi: 10.1109/TPWRD.2018.2882431.

[4] G. Liu, F. Xu, Z. Xu, Z. Zhang and G. Tang, "Assembly HVDC Breaker for HVDC Grids With Modular Multilevel Converters," in IEEE Transactions on Power Electronics, vol. 32, no. 2, pp. 931-941, Feb. 2017, doi: 10.1109/TPEL.2016.2540808.

[5] X. Han, W. Sima, M. Yang, L. Li, T. Yuan and Y. Si, "Transient Characteristics Under Ground and Short-Circuit Faults in a $\pm 500 \mathrm{kV}$ MMC-Based HVDC System With Hybrid DC Circuit Breakers," in IEEE Transactions on Power Delivery, vol. 33, no. 3, pp. 1378-1387, June 2018, doi: 10.1109/TPWRD.2018.2795800.

[6] M. N. Haleem and A. D. Rajapakse, "Fault Type Discrimination in HVDC Transmission Lines Using Rate of Change of Local Currents," in IEEE Transactions on Power Delivery. doi: 10.1109/TPWRD.2019.2922944

[7] J. Sneath and A. D. Rajapakse, "Fault Detection and Interruption in an Earthed HVDC Grid Using ROCOV and Hybrid DC Breakers," in IEEE Transactions on Power Delivery, vol. 31, no. 3, pp. 973-981, June 2016.

[8] R. Li, L. Xu and L. Yao, "DC Fault Detection and Location in Meshed Multiterminal HVDC Systems Based on DC Reactor Voltage Change Rate," in IEEE Transactions on Power Delivery, vol. 32, no. 3, pp. 1516-1526, June 2017. 
[9] J. Liu, N. Tai and C. Fan, "Transient-Voltage-Based Protection Scheme for DC Line Faults in the Multiterminal VSC-HVDC System," in IEEE Transactions on Power Delivery, vol. 32, no. 3, pp. 1483-1494, June 2017.

[10] Z. Dai, N. Liu, C. Zhang, X. Pan and J. Wang, "A Pilot Protection for HVDC Transmission Lines Based on Transient Energy Ratio of DC Filter Link," in IEEE Transactions on Power Delivery. doi: 10.1109/TPWRD.2019.2950350

[11] S. Li, W. Chen, X. Yin, D. Chen and Y. Teng, "A Novel Integrated Protection for VSC-HVDC Transmission Line Based on Current Limiting Reactor Power," in IEEE Transactions on Power Delivery. doi: 10.1109/TPWRD.2019.2945412

[12] C. Li, A. M. Gole and C. Zhao, "A Fast DC Fault Detection Method Using DC Reactor Voltages in HVdc Grids," in IEEE Transactions on Power Delivery, vol. 33, no. 5, pp. 2254-2264, Oct. 2018.

[13] W. Xiang, S. Yang, L. Xu, J. Zhang, W. Lin and J. Wen, "A Transient Voltage-Based DC Fault Line Protection Scheme for MMC-Based DC Grid Embedding DC Breakers," in IEEE Transactions on Power Delivery, vol. 34, no. 1, pp. 334-345, Feb. 2019. doi: 10.1109/TPWRD.2018.2874817

[14] S. Yang, W. Xiang, R. Li, X. Lu, W. Zuo and J. Wen, "An Improved DC fault Protection Algorithm for MMC HVDC Grids based on Modal Domain Analysis," in IEEE Journal of Emerging and Selected Topics in Power Electronics. doi: 10.1109/JESTPE.2019.2945200

[15] Y. M. Yeap, N. Geddada, and A. Ukil, âAnalysis and validation of wavelet transform based DC fault detection in HVDC system,â in Appl. Soft Comput., vol. 61, pp. 127â137, 2017

[16] V. Nougain, V. Nougain and S. Mishra, "Low-voltage DC ring-bus microgrid protection with rolling mean technique," 2018 IEEMA Engineer Infinite Conference (eTechNxT), New Delhi, 2018, pp. 1-6.

[17] Vrana, T. K., Yang, Y., Jovcic, D., Dennetiere, S., Jardini, J., Saad, H. (2013). The CIGRE B4 DC Grid Test System. Electra, (270), 10-19.

[18] E. Kontos, R. T. Pinto, S. Rodrigues and P. Bauer, "Impact of HVDC Transmission System Topology on Multiterminal DC Network Faults," in IEEE Transactions on Power Delivery, vol. 30, no. 2, pp. 844-852, April 2015, doi: 10.1109/TPWRD.2014.2357056.

[19] C. Li, C. Zhao, J. Xu, Y. Ji, F. Zhang and T. An, "A Pole-to-Pole ShortCircuit Fault Current Calculation Method for DC Grids," in IEEE Transactions on Power Systems, vol. 32, no. 6, pp. 4943-4953, Nov. 2017, doi: 10.1109/TPWRS.2017.2682110.

[20] P. T. Lewis, B. M. Grainger, H. A. Al Hassan, A. Barchowsky and G. F Reed, "Fault Section Identification Protection Algorithm for Modular Multilevel Converter-Based High Voltage DC With a Hybrid Transmission Corridor," in IEEE Transactions on Industrial Electronics, vol. 63, no. 9, pp. 5652-5662, Sept. 2016.

[21] X. Li, Q. Song, W. Liu, H. Rao, S. Xu and L. Li, "Protection of Nonpermanent Faults on DC Overhead Lines in MMC-Based HVDC Systems," in IEEE Transactions on Power Delivery, vol. 28, no. 1, pp. 483-490, Jan. 2013.

[22] J. Yang, J. E. Fletcher and J. O'Reilly, "Short-Circuit and Ground Fault Analyses and Location in VSC-Based DC Network Cables," in IEEE Transactions on Industrial Electronics, vol. 59, no. 10, pp. 3827-3837, Oct. 2012.

[23] Y. Chen, S. Zhao, Z. Li, X. Wei and Y. Kang, "Modeling and Control of the Isolated DC-DC Modular Multilevel Converter for Electric Ship Medium Voltage Direct Current Power System," in IEEE Journal of Emerging and Selected Topics in Power Electronics, vol. 5, no. 1, pp. 124-139, March 2017.

[24] G. Li, J. Liang, C. E. Ugalde-Loo, F. Ma, H. Liang and Z. Song, "Protection for Submodule Overvoltage caused by Converter ValveSide Single-Phase-to-Ground Faults in FB-MMC based Bipolar HVDC Systems," in IEEE Transactions on Power Delivery, doi: 10.1109/TPWRD.2020.2974413.

[25] M. Langwasser, G. De Carne, M. Liserre and M. Biskoping, "Fault Current Estimation in Multi-Terminal HVdc Grids Considering MMC Control," in IEEE Transactions on Power Systems, vol. 34, no. 3, pp. 2179-2189, May 2019, doi: 10.1109/TPWRS.2018.2887166.

[26] J. Li, Y. Li, L. Xiong, K. Jia and G. Song, "DC Fault Analysis and Transient Average Current Based Fault Detection for Radial MTDC System," in IEEE Transactions on Power Delivery, vol. 35, no. 3, pp. 1310-1320, June 2020, doi: 10.1109/TPWRD.2019.2941054.

[27] A. MALKHANDI, N. Senroy and S. Mishra, "Return Ratio Shaping Approach to Stabilize Inverter-Weak Grid System," in IEEE Transactions on Energy Conversion, doi: 10.1109/TEC.2020.3003074.

[28] J. Xu, Y. Lü, C. Zhao and J. Liang, "A Model-Based DC Fault Location Scheme for Multi-Terminal MMC-HVDC Systems Using a Simplified
Transmission Line Representation," in IEEE Transactions on Power Delivery, vol. 35, no. 1, pp. 386-395, Feb. 2020.

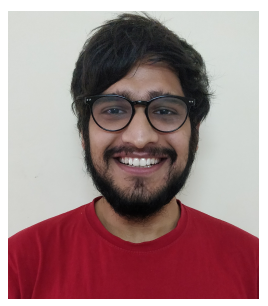

Vaibhav Nougain received B.Tech degree in electrical engineering in 2017 from Delhi Technological University (Formerly Delhi College of Engineering), New Delhi, India. He is currently working toward the Ph.D. degree at the Department of Electrical Engineering, Indian Institute of Technology Delhi, New Delhi, India. He was a Visiting Student with The Center for Electric Power and Energy (CEE), Technical University of Denmark in 2019. His research interests include coordinated protection and control of DC microgrids, and protection of HVDC systems.

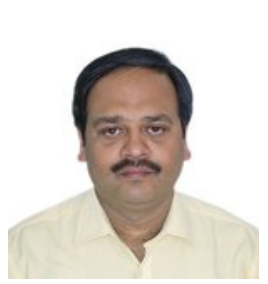

Sukumar Mishra (Senior Member, IEEE) received his $\mathrm{M}$.Tech and $\mathrm{PhD}$ in Electrical Engineering from National Institute of Technology, Rourkela in 1992 and 2000 respectively. Presently, Dr. Mishra is a Professor at the Indian Institute of Technology Delhi and has been its part for the past 17 years. He has won many accolades such as INSA Medal for Young Scientist (2002), INAE Young Engineer Award (2009, 2002), INAE Silver Jubilee Young Engineer Award (2012), Samanta Chandra Shekhar Award (2016), IETE Bimal Bose award (2019), National Mission Innovation Champion award (2019) and NASI-Reliance Industries Platinum Jubilee Award for Application Oriented Innovation in Physical Sciences (2019). He has been granted fellowships from academies like NASI (India), INAE (India), and professional societies like IET (U.K.), IETE (India), IE (India). He has also been recognized as the INAE Industry Academic Distinguished Professor. His research interests lie in the field of Power Systems, Power Quality Studies, Renewable Energy and Smart Grid.

Prof. Mishra is currently acting as the ABB Chair professor and has previously delegated as the NTPC, INAE, and Power Grid Chair professor. He has also served as an Independent Director of the Cross Border Power Transmission Company Ltd. and the River Engineering Pvt. Ltd. And has carried out many important industrial consultations with TATA Power, Microtek and others. He is the founder of SILOV SOLUTIONS PRIVATE LIMITED, a company that specifically deals in products related to renewable energy sources utilizable at household scale as well as at commercial setups. From March 2020, he has also been functioning as the Associate Dean Research and Development of IIT Delhi. Prof. Mishra has been working in close association with IEEE Delhi Section Executive Committee for the past few years and is currently serving as an Editor for the IEEE Transactions on Smart Grid, IEEE Transactions on Sustainable Energy and was an Area Editor for the IET Generation, Transmission Distribution journal. 


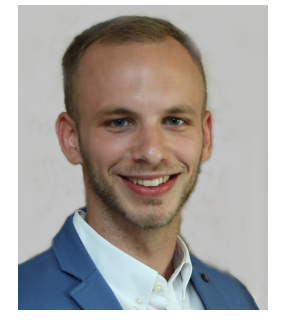

George Misyris ( $\left.\mathrm{S}^{\prime} 15\right)$ was born in Thessaloniki, Greece, in 1992. He received the Dipl.-Eng. degree in electrical and computer engineering from the Aristotle University of Thessaloniki, Thessaloniki, Greece. In 2016, he joined ABB Corporate Research, Västerås, Sweden. Since, 2017, he has been working toward the Ph.D. degree at the Denmark Technical University, Lyngby, Denmark. His research interests are power system modeling, control of AC and HVDC grids, machine learning applications for power systems as well as battery energy storage systems.

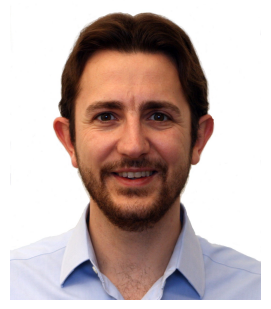

Spyros Chatzivasileiadis (S'04, M'14, $\mathrm{SM}^{\prime} 18$ ) is an Associate Professor at the Technical University of Denmark (DTU) and the Acting Group Leader of the Energy Analytics and Markets Group at the Center for Electric Power and Energy at DTU. Before that he was a postdoctoral researcher at the Massachusetts Institute of Technology (MIT), USA and at Lawrence Berkeley National Laboratory, USA. Spyros holds a PhD from ETH Zurich, Switzerland (2013) and a Diploma in Electrical and Computer Engineering from the National Technical University of Athens (NTUA), Greece (2007). He is currently working on machine learning applications for power systems, and on power system optimization, dynamics, and control of AC and HVDC grids. Spyros is the recipient of an ERC Starting Grant in 2020. 